\title{
Transition probabilities in Te II and Te III spectra ${ }^{\star}$
}

\author{
W. Zhang ${ }^{1}$, P. Palmeri ${ }^{1}$, P. Quinet ${ }^{1,2}$, and É. Biémont ${ }^{1,2}$ \\ 1 Astrophysique et Spectroscopie, Université de Mons - UMONS, Place du Parc 20, 7000 Mons, Belgium \\ 2 IPNAS (Bât. B15), Université de Liège, Sart Tilman, 4000 Liège, Belgium \\ e-mail: Patrick.Palmeri@umons.ac.be
}

Received 14 December 2012 / Accepted 5 February 2013

\begin{abstract}
Context. Due to the need of transition probabilities for heavy ions, including those of tellurium, in different fields of physics and in astrophysics, we have investigated theoretically the atomic structure of two selected tellurium ions $\left(\mathrm{Te}^{+}\right.$and $\left.\mathrm{Te}^{++}\right)$for which no theoretical data were available so far.

Aims. The first transition probabilities have been calculated for the electric dipole (E1) transitions with wavelengths shorter than 1 micrometer in Te II-III.

Methods. Both the multiconfiguration Dirac-Hartree-Fock (MCDHF) method and the relativistic Hartree-Fock (HFR) approach, in which core-polarization (CPOL) effects were included, have been used for the calculations.

Results. The results obtained with these two completely independent methods are in reasonable agreement. As a consequence, the transition probabilities obtained in this work are expected to be reliable. They fill in a gap concerning the radiative parameters in these two ions.
\end{abstract}

Key words. atomic data - atomic processes

\section{Introduction}

Tellurium is important in astrophysics and, more particularly, in stellar nucleosynthesis. In 1973 already, Cowley et al. (1973) were able to obtain abundance estimates for 8 elements in the star HR 465 near the r-process peaks at tellurium and osmium. A large overabundance of tellurium was obtained by assuming that the oscillator strengths were equal to $\log g f=0.0$, which was obviously a rough approximation imposed by the lack of data on oscillator strengths. Recently, neutral tellurium has been detected by Roederer et al. (2012) in three metal-poor stars (BD + 17 3248, HD 108317, and HD 128279) enriched by products of r-process nucleosynthesis using near-ultraviolet spectra obtained with the Space Telescope Imaging Spectrograph on board the Hubble Space Telescope. This element had not been detected previously in Galactic halo stars.

The tellurium ions $\left(\mathrm{Te}^{+}\right.$and $\mathrm{Te}^{2+}$ ) have not been identified so far in stellar spectra, one of the obvious reasons being the lack of data on oscillator strengths in these two ions, the results available (Biémont et al. 1995) concerning only the forbidden transitions. Another reason results from the fact that a quantitative analysis of Te II lines is complicated by hyperfine structure effects (Werel $\&$ Augustyniak 1981). This lack of radiative data justifies the effort of the present work. It is further motivated by the recent new analysis of Te III spectrum carried out by Tauheed \& Naz (2011).

\footnotetext{
* Tables 8 and 9 are only available in electronic form at the CDS via anonymous ftp to cdsarc.u-strasbg. fr (130.79.128.5) or via http://cdsarc.u-strasbg.fr/viz-bin/qcat?]/A+A/551/A136
}

\section{State-of-the-art analysis of Te II and Te III spectra}

The ground configuration of Te II is $5 \mathrm{~s}^{2} 5 \mathrm{p}^{3}$. The experimentally known even configurations are $5 \mathrm{~s} 5 \mathrm{p}^{4}, 5 \mathrm{~s}^{2} 5 \mathrm{p}^{2} n \mathrm{~d}(n \geq 5)$ and $5 s^{2} 5 p^{2} n s(n \geq 6)$. The excited odd ones are of the types $5 \mathrm{~s}^{2} 5 \mathrm{p}^{2} n \mathrm{p}(n \geq 6)$ and $5 \mathrm{~s}^{2} 5 \mathrm{p}^{2} n \mathrm{f}(n \geq 4)$. The levels compiled in the NIST database (Kramida et al. 2012) are taken from Handrup $\&$ Mack (1964) and are characterized by an uncertainty of about $0.2 \mathrm{~cm}^{-1}$. More accurate level values of the ground configuration (uncertainties in the range $0.004-0.007 \mathrm{~cm}^{-1}$ ) are due to Eriksson (1974). The most recent Te II spectrum analysis is due to Tauheed et al. (2009) but the uncertainties are larger $\left(0.4-2.3 \mathrm{~cm}^{-1}\right)$. The levels considered in the present work have been adopted from the NIST compilation.

Te III belongs to the Sn I isoelectronic sequence and its ground configuration is $5 \mathrm{~s}^{2} 5 \mathrm{p}^{2}$. The excitation of an outer electron from the ground configuration leads to $5 \mathrm{~s}^{2} 5 \mathrm{p} n \mathrm{~d}(n \geq 5)$ and $5 \mathrm{~s}^{2} 5 \mathrm{p} n \mathrm{~s}(n \geq 6)$ while the core excitation gives rise to the $5 \mathrm{~s} 5 \mathrm{p}^{3}$ configuration. The first investigations of the Te III spectrum are due to Krishnamurty \& Rao (1937) and Joshi \& Crooker (1964). More recently, the analysis of the Te III spectrum was revised on the basis of configuration interaction calculations by Joshi et al. (1992) but this work was restricted to transitions connecting the ground configuration and $5 \mathrm{~s}^{2} 5 \mathrm{p} 5 \mathrm{~d}, 5 \mathrm{~s}^{2} 5 \mathrm{p} 6 \mathrm{~s}$ and $5 \mathrm{~s} 5 \mathrm{p}^{3}$ configurations. The most recent effort in this ion is due to Tauheed \& Naz (2011) who investigated the VUV region (30-200 nm). 150 lines were identified and 60 energy levels were established. The present work is essentially based on this analysis.

The prominent lines of Te II emitted from the ground state configuration $\left(5 s^{2} 5 p^{3}\right)$ do appear in the short wavelength range between 79 and $184 \mathrm{~nm}$. In Te III, according to Tauheed \& Naz (2011), the lines emitted from the ground $5 \mathrm{~s}^{2} 5 \mathrm{p}^{2}$ 
configuration are observed in the $50-75 \mathrm{~nm}$ wavelength range. However, Joshi et al. (1992) have observed Te III lines between $77-178 \mathrm{~nm}$.

\section{Calculations}

A traditional way to obtain transition probabilities in a given ion is to combine lifetime measurements (realized e.g. with a laser spectroscopy technique) with branching fractions deduced either from direct measurements in the laboratory or from atomic structure calculations. When the experimental lifetimes are entirely missing, it is necessary to rely on atomic structure calculations. The accuracy of such calculations is difficult to evaluate particularly in the case of heavy ions or atoms. An interesting information on this accuracy is obtained by comparing calculations realized using several different independent theoretical approaches. The agreement (or disagreement) observed when comparing the different sets of results allows to assess the validity of the theoretical models used. This general procedure was followed in the present work.

\subsection{MCDHF calculations in Te II and Te III}

A first approach used is the multiconfiguration Dirac-HartreeFock (MCDHF) method implemented in the GRASP2K computer package (Jonsson et al. 2007). In this method, the atomic state functions (ASFs), $\Psi\left(\gamma \mathrm{JM}_{J}\right)$, are expanded in linear combinations of configuration state functions (CSFs), $\Phi\left(\alpha_{i} \mathrm{JM}_{J}\right)$, according to:

$\Psi\left(\gamma \mathrm{JM}_{J}\right)=\sum_{i} c_{i} \Phi\left(\alpha_{i} \mathrm{JM}_{J}\right)$

The CSFs are in turn linear combinations of Slater determinants obtained from monoelectronic spin orbitals of the form:

$\varphi_{n \kappa m}(r, \theta, \phi)=\frac{1}{r}\left(\begin{array}{c}P_{n \kappa}(r) \chi_{\kappa m}(\theta, \phi) \\ \mathrm{i} Q_{n \kappa}(r) \chi_{-\kappa m}(\theta, \phi)\end{array}\right)$,

where $P_{n \kappa}(r)$ and $Q_{n \kappa}(r)$ are, respectively, the large and the small component of the radial wave functions, and the angular functions $\chi_{\kappa m}(\theta, \phi)$ are the spinor spherical harmonics (Grant 1988). The $\alpha_{i}$ represent all the one-electron and intermediate quantum numbers needed to completely define the CSF. $\gamma$ is usually chosen as the $\alpha_{i}$ corresponding to the CSFs with the largest weight $\left|c_{i}\right|^{2}$. The quantum number $\kappa$ is given by:

$\kappa= \pm\left(j+\frac{1}{2}\right)$

where $j$ is the electron total angular momentum. The sign before the parentheses in Eq. (3) corresponds to the coupling relation between the electron orbital momentum, 1, and its spin, i.e.,

$l=j \pm \frac{1}{2}$.

The radial functions $P_{n \kappa}(r)$ and $Q_{n \kappa}(r)$ are numerically represented on a logarithmic grid and are required to be orthonormal within each $\kappa$ symmetry. In the MCDHF variational procedure, the radial functions and the expansion coefficients $c_{i}$ are optimized to self-consistency.

We have considered the restricted active space (RAS) method for building the MCDHF multiconfiguration expansions.
The latter are produced by exciting the electrons from the reference configurations to a given set of orbitals. The rules adopted for generating the configuration space differ according to the correlation model being used. Within a given correlation model, the active set of orbitals spanning the configuration space is increased to monitor the convergence of the total energies and the transition probabilities.

Our calculations have been focused on the E1 transitions $5 \mathrm{~s}^{2} 5 \mathrm{p}^{k}-\left(5 \mathrm{~s} 5 \mathrm{p}^{k+1}+5 \mathrm{~s}^{2} 5 \mathrm{p}^{k-1} n l\right)$ with $n l=5 \mathrm{~d}, 6 \mathrm{~s}, 6 \mathrm{p}$ and $k=3$ in Te II and $k=2$ in Te III. They have been carried out in six steps for each ion.

In the first step, the core orbitals, i.e. 1 s to $4 \mathrm{~d}$, together with the $5 \mathrm{~s}$ and $5 \mathrm{p}$ orbitals, have been optimized. All the CSFs ( 6 in Te II and 5 in Te III) belonging to the ground configuration $5 s^{2} 5 p^{k}$ were retained in the configuration space. The energy functional was built within the framework of the average level (AL) option (Grant 1988).

The second step consisted in increasing the configuration space by considering all the CSFs (70 in Te II and 41 in Te III) belonging to the following configurations: $5 \mathrm{~s}^{2} 5 \mathrm{p}^{k}+5 \mathrm{~s} 5 \mathrm{p}^{k+1}+$ $5 s^{2} 5 p^{k-1}\{5 \mathrm{~d}, 6 \mathrm{~s}, 6 \mathrm{p}\}^{1}$. The $5 \mathrm{~d}, 6 \mathrm{~s}$, and $6 \mathrm{p}$ orbitals have been optimized, keeping the others fixed to their values of the first step. The AL option was chosen to build the energy functional.

In the third step, the configuration space has been extended to, respectively, 12037 in Te II and 4386 in Te III by considering single and double virtual excitations to the active orbital set $\{5 \mathrm{~s}, 5 \mathrm{p}, 5 \mathrm{~d}, 6 \mathrm{~s}, 6 \mathrm{p}, 6 \mathrm{~d}\}$ from the multi-reference configurations $5 \mathrm{~s}^{2} 5 \mathrm{p}^{k}+5 \mathrm{~s} 5 \mathrm{p}^{k+1}+5 \mathrm{~s}^{2} 5 \mathrm{p}^{k-1}\{5 \mathrm{~d}, 6 \mathrm{~s}, 6 \mathrm{p}\}^{1}$. Only the $6 \mathrm{~d}$ orbital has been optimized, fixing all the others to the values of the preceding step using an energy functional built from the lowest 70 ASFs in Te II and the lowest 41 ASFs in Te III within the framework of the extended optimal level (EOL) option (Grant 1988). One can note that, from this step of the computation and onward, core-valence and core-core correlations are also considered through single and double excitations of the $5 \mathrm{~s}$ core electrons, respectively.

The last three steps consisted in extending further the configuration space by adding to the active set of the preceding steps the following orbitals: $7 \mathrm{~s}, 7 \mathrm{p}$, and $7 \mathrm{~d}$ in the fourth step giving rise to $37226 \mathrm{CSFs}$ in Te II and 12812 CSFs in Te III; $8 \mathrm{~s}, 8 \mathrm{p}$, and $8 \mathrm{~d}$ in the fifth step generating $76611 \mathrm{CSF}$ in Te II and 25802 CSFs in Te III; and finally, 4f in the last step with 102359 and 32724 CSFs generated in Te II and Te III, respectively. In these steps, only the added orbitals have been optimized, the others being fixed using the same energy functional as in the third step; also, single and double virtual electron excitations from the same multi-reference configurations as in the third step have been used to generate the configuration spaces. In Te II, further orbital additions to the active set as well as further opening of the core to include more core-valence and core-core correlations have been prevented by the memory limitations of our computer. We did not attempt to extend further our MCDHF calculation in Te III in order to keep a model equivalent to the one used in Te II.

The comparisons between the experimental (Kramida et al. 2012; Tauheed \& Naz 2011) and our MCDHF level energies and Landé factors are shown in Tables 1 and 2 for Te II and Te III, respectively. One can notice that the core-excited levels belonging to $5 \mathrm{~s} 5 \mathrm{p}^{k+1}$ have larger deviations from the experimental energies. This may be explained by the missing core-valence and core-core correlations with the opening of the $n \leq 4$ core shells that are implicitly taken into account in our HFR+CPOL calculation through a polarization potential and a fitting procedure (see the next section). 
W. Zhang et al.: Transition probabilities in Te II and Te III spectra

Table 1. Comparison between experimental and MCDHF level energies and Landé factors in Te II.

\begin{tabular}{|c|c|c|c|c|c|c|}
\hline Designation $^{a}$ & $\begin{array}{l}E_{\mathrm{DHF}^{b}}^{b} \\
\left(\mathrm{~cm}^{-1}\right)\end{array}$ & $\begin{array}{c}E_{\operatorname{Exp}}^{a} \\
\left(\mathrm{~cm}^{-1}\right)\end{array}$ & $\begin{array}{c}\Delta E^{c} \\
\left(\mathrm{~cm}^{-1}\right)\end{array}$ & $g_{\mathrm{DHF}}^{b}$ & $g_{\operatorname{Exp}}{ }^{a}$ & $g_{\mathrm{DHF}} / g_{\text {Exp }}$ \\
\hline $5 s^{2} 5 p^{3}{ }^{4} S_{3 / 2}^{\circ}$ & 0 & 0.000 & 0 & 1.96 & 1.93 & 1.02 \\
\hline $5 s^{2} 5 p^{32} \mathrm{D}_{3 / 2}^{\circ}$ & 11048 & 10222.385 & 826 & 0.90 & & \\
\hline $5 s^{2} 5 p^{32} D_{5 / 2}^{\circ}$ & 13100 & 12421.854 & 678 & 1.20 & & \\
\hline $5 \mathrm{~s}^{2} 5 \mathrm{p}^{32} \mathrm{P}_{1 / 2}^{\circ}$ & 21496 & 20546.591 & 949 & 0.67 & & \\
\hline $5 \mathrm{~s}^{2} 5 \mathrm{p}^{3}{ }^{2} \mathrm{P}_{3 / 2}^{\circ}$ & 24603 & 24032.095 & 571 & 1.27 & 1.27 & 1.00 \\
\hline $5 s 5 p^{4}\left({ }^{3} P\right){ }^{4} P_{5 / 2}$ & 67933 & 71192.526 & -3260 & 1.59 & 1.59 & 1.00 \\
\hline $5 s 5 p^{4}\left({ }^{3} \mathrm{P}\right){ }^{4} \mathrm{P}_{3 / 2}$ & 71416 & 74893.40 & -3477 & 1.72 & 1.71 & 1.00 \\
\hline $5 \mathrm{~s} 5 \mathrm{p}^{4}\left({ }^{3} \mathrm{P}\right){ }^{4} \mathrm{P}_{1 / 2}$ & 72866 & 76300.87 & -3435 & 2.65 & 2.63 & 1.01 \\
\hline $5 s^{2} 5 p^{2}\left({ }^{3} P\right) 6 s{ }^{4} P_{1 / 2}$ & 77595 & 78448.22 & -853 & 2.35 & 2.29 & 1.02 \\
\hline $5 s^{2} 5 p^{2}\left({ }^{3} \mathrm{P}\right) 5 d^{2} \mathrm{P}_{3 / 2}$ & 80856 & 81895.43 & -1039 & 1.10 & 1.12 & 0.98 \\
\hline $5 s^{2} 5 p^{2}\left({ }^{3} P\right) 6 s^{4} P_{3 / 2}$ & 81595 & 82743.33 & -1148 & 1.50 & 1.45 & 1.04 \\
\hline $5 s^{2} 5 p^{2}\left({ }^{3} P\right) 6 s^{2} P_{3 / 2}$ & 82815 & 83577.41 & -762 & 0.98 & 1.06 & 0.93 \\
\hline $5 s^{2} 5 p^{2}\left({ }^{3} P\right) 5 d^{4} F_{5 / 2}$ & 84059 & 85049.41 & -990 & 1.11 & 1.09 & 1.02 \\
\hline $5 s^{2} 5 p^{2}\left({ }^{3} P\right) 5 d^{4} F_{3 / 2}$ & 84232 & 85159.66 & -928 & 0.81 & 0.88 & 0.92 \\
\hline $5 s^{2} 5 p^{2}\left({ }^{3} P\right) 6 s{ }^{4} P_{5 / 2}$ & 84487 & 85591.83 & -1105 & 1.50 & 1.50 & 1.00 \\
\hline $5 \mathrm{~s} 5 \mathrm{p}^{4}\left({ }^{1} \mathrm{D}\right){ }^{2} \mathrm{D}_{3 / 2}$ & 85447 & 86759.90 & -1313 & 0.93 & 0.94 & 0.99 \\
\hline $5 s 5 p^{4}\left({ }^{1} D\right){ }^{2} D_{5 / 2}$ & 85714 & 87404.54 & -1691 & 1.23 & 1.25 & 0.99 \\
\hline $5 s^{2} 5 p^{2}\left({ }^{3} P\right) 5 d^{4} F_{7 / 2}$ & 86979 & 87899.86 & -921 & 1.26 & 1.26 & 1.00 \\
\hline $5 s^{2} 5 p^{2}\left({ }^{3} \mathrm{P}\right) 5 d^{2} \mathrm{P}_{1 / 2}$ & 87819 & 88796.16 & -977 & 0.38 & 0.35 & 1.09 \\
\hline $5 s^{2} 5 p^{2}\left({ }^{3} \mathrm{P}\right) 6 s^{2} \mathrm{P}_{3 / 2}$ & 87978 & 88961.09 & -983 & 1.19 & 1.17 & 1.02 \\
\hline $5 s^{2} 5 p^{2}\left({ }^{3} P\right) 5 d^{2} F_{5 / 2}$ & 88307 & 88924.81 & -618 & 0.95 & 0.94 & 1.01 \\
\hline $5 s^{2} 5 p^{2}\left({ }^{3} P\right) 5 d^{4} F_{9 / 2}$ & 89591 & 90519.67 & -929 & 1.32 & 1.31 & 1.00 \\
\hline $5 s^{2} 5 p^{2}\left({ }^{1} D\right) 5 d^{2} F_{7 / 2}$ & 90029 & 90797.21 & -768 & 1.27 & 1.25 & 1.01 \\
\hline $5 s^{2} 5 p^{2}\left({ }^{3} P\right) 5 d^{4} D_{3 / 2}$ & 91068 & 92191.47 & -1123 & 1.14 & 1.13 & 1.00 \\
\hline $5 s^{2} 5 p^{2}\left({ }^{3} P\right) 5 d^{4} D_{1 / 2}$ & 91605 & 92691.51 & -1087 & 0.37 & 0.42 & 0.88 \\
\hline $5 s^{2} 5 p^{2}\left({ }^{3} P\right) 5 d^{4} D_{5 / 2}$ & 91939 & 92793.22 & -854 & 1.23 & 1.24 & 0.99 \\
\hline $5 s^{2} 5 p^{2}\left({ }^{3} P\right) 6 p^{4} D_{1 / 2}^{\circ}$ & 93115 & 93978.93 & -864 & 0.84 & 0.79 & 1.06 \\
\hline $5 s^{2} 5 p^{2}\left({ }^{1} D\right) 6 s^{2} D_{5 / 2}$ & 94016 & 94860.63 & -845 & 1.26 & 1.27 & 0.99 \\
\hline $5 s^{2} 5 p^{2}\left({ }^{1} D\right) 6 s^{2} D_{3 / 2}$ & 94394 & 95208.37 & -814 & 0.96 & 0.98 & 0.98 \\
\hline $5 s^{2} 5 p^{2}\left({ }^{3} P\right) 6 p^{4} D_{7 / 2}^{\circ}$ & 95213 & 96144.74 & -932 & 1.33 & 1.32 & 1.00 \\
\hline $5 s^{2} 5 p^{2}\left({ }^{3} P\right) 5 d^{4} D_{7 / 2}$ & 95668 & 96534.6 & -867 & 1.25 & 1.24 & 1.01 \\
\hline $5 s^{2} 5 p^{2}\left({ }^{3} P\right) 6 p^{2} S_{1 / 2}^{\circ}$ & 96539 & 97780.09 & -1241 & 1.21 & 1.26 & 0.96 \\
\hline $5 s^{2} 5 p^{2}\left({ }^{3} P\right) 6 p^{4} S_{3 / 2}^{\circ}$ & 98484 & 99584.59 & -1101 & 1.30 & 1.26 & 1.04 \\
\hline $5 s^{2} 5 p^{2}\left({ }^{3} P\right) 6 p^{4} D_{5 / 2}^{\circ}$ & 98901 & 100112.10 & -1211 & 1.40 & 1.4 & 1.00 \\
\hline $5 s^{2} 5 p^{2}\left({ }^{3} P\right) 6 p^{2} D_{3 / 2}^{\circ}$ & 100031 & 101220.97 & -1190 & 1.26 & 1.31 & 0.97 \\
\hline $5 s^{2} 5 p^{2}\left({ }^{3} P\right) 5 d^{4} P_{5 / 2}$ & 100052 & 99229.68 & 822 & 1.53 & 1.51 & 1.01 \\
\hline $5 s^{2} 5 p^{2}\left({ }^{3} P\right) 6 p^{4} P_{1 / 2}^{\circ}$ & 100112 & 101370.86 & -1259 & 2.35 & 2.33 & 1.01 \\
\hline $5 \mathrm{~s}^{2} 5 \mathrm{p}^{2}\left({ }^{1} \mathrm{D}\right) 5 \mathrm{~d}^{2} \mathrm{~S}_{1 / 2}$ & 100528 & 101065.37 & -537 & 1.99 & 2.12 & 0.94 \\
\hline $5 \mathrm{~s}^{2} 5 \mathrm{p}^{2}\left({ }^{1} \mathrm{D}\right) 5 \mathrm{~d}^{2} \mathrm{G}_{7 / 2}$ & 101082 & 100835.8 & 246 & 0.94 & 0.98 & 0.96 \\
\hline $5 \mathrm{~s}^{2} 5 \mathrm{p}^{2}\left({ }^{3} \mathrm{P}\right) 6 \mathrm{p}^{4} \mathrm{P}_{3 / 2}^{\circ}$ & 101273 & 102324.49 & -1051 & 1.33 & 1.31 & 1.02 \\
\hline $5 s^{2} 5 p^{2}\left({ }^{3} P\right) 5 d^{4} P_{3 / 2}$ & 101551 & 100740.75 & 810 & 1.53 & 1.56 & 0.98 \\
\hline $5 s^{2} 5 p^{2}\left({ }^{3} P\right) 6 p^{4} D_{7 / 2}^{\circ}$ & 101948 & 103105.86 & -1158 & 1.39 & 1.38 & 1.00 \\
\hline $5 s^{2} 5 p^{2}\left({ }^{3} P\right) 6 p^{4} P_{3 / 2}^{\circ}$ & 102681 & 103935.90 & -1255 & 1.75 & 1.74 & 1.01 \\
\hline $5 s^{2} 5 p^{2}\left({ }^{3} P\right) 5 d^{2} D_{3 / 2}$ & 102711 & 102244.60 & 466 & 0.98 & 0.95 & 1.03 \\
\hline $5 s^{2} 5 p^{2}\left({ }^{3} P\right) 5 d^{4} P_{1 / 2}$ & 102764 & 102127.22 & 637 & 2.42 & 2.26 & 1.07 \\
\hline $5 s^{2} 5 p^{2}\left({ }^{3} P\right) 5 d^{2} D_{5 / 2}$ & 103708 & 102703.5 & 1005 & 1.10 & 1.12 & 0.99 \\
\hline $5 \mathrm{~s}^{2} 5 \mathrm{p}^{2}\left({ }^{3} \mathrm{P}\right) 6 \mathrm{p}^{2} \mathrm{P}_{3 / 2}^{\circ}$ & 104065 & 105006.08 & -941 & 1.22 & 1.21 & 1.01 \\
\hline $5 s^{2} 5 p^{2}\left({ }^{3} P\right) 6 p^{2} D_{5 / 2}^{\circ}$ & 104461 & 105583.02 & -1122 & 1.29 & 1.29 & 1.00 \\
\hline $5 \mathrm{~s}^{2} 5 \mathrm{p}^{2}\left({ }^{3} \mathrm{P}\right) 6 \mathrm{p}^{2} \mathrm{P}_{1 / 2}^{\circ}$ & 105086 & 106119.20 & -1033 & 0.86 & 0.87 & 0.99 \\
\hline $5 s^{2} 5 p^{2}\left({ }^{1} S\right) 6 s^{2} S_{1 / 2}$ & 108090 & 109005.8 & -916 & 1.70 & & \\
\hline $5 \mathrm{~s}^{2} 5 \mathrm{p}^{2}\left({ }^{3} \mathrm{P}\right) 5 \mathrm{~d}^{2} \mathrm{~F}_{7 / 2}$ & 108210 & 107244.4 & 966 & 1.12 & 1.19 & 0.94 \\
\hline $5 s^{2} 5 p^{2}\left({ }^{1} D\right) 5 d^{2} P_{1 / 2}$ & 108768 & 107521.8 & 1246 & 1.14 & & \\
\hline $5 s^{2} 5 p^{2}\left({ }^{1} D\right) 5 d^{2} F_{5 / 2}$ & 109538 & 108819.4 & 719 & 1.01 & & \\
\hline $5 s^{2} 5 p^{2}\left({ }^{3} P\right) 6 p^{2} D_{5 / 2}^{\circ}$ & 110944 & 111946.69 & -1003 & 1.19 & 1.19 & 1.00 \\
\hline $5 \mathrm{~s}^{2} 5 \mathrm{p}^{2}\left({ }^{1} \mathrm{D}\right) 5 \mathrm{~d}^{2} \mathrm{P}_{3 / 2}$ & 111177 & 110136.3 & 1041 & 1.34 & & \\
\hline $5 \mathrm{~s}^{2} 5 \mathrm{p}^{2}\left({ }^{1} \mathrm{D}\right) 6 \mathrm{p}^{2} \mathrm{D}_{3 / 2}^{\circ}$ & 111303 & 112272.43 & -969 & 1.05 & 1.09 & 0.96 \\
\hline $5 s^{2} 5 p^{2}\left({ }^{1} D\right) 6 p^{2} F_{5 / 2}^{\circ}$ & 111690 & 112548.84 & -859 & 1.02 & 1.06 & 0.96 \\
\hline $5 s^{2} 5 p^{2}\left({ }^{1} \mathrm{D}\right) 6 \mathrm{p}^{2} \mathrm{~F}_{7 / 2}^{\circ}$ & 111934 & 112788.49 & -854 & 1.19 & 1.20 & 0.99 \\
\hline $5 \mathrm{~s}^{2} 5 \mathrm{p}^{2}\left({ }^{1} \mathrm{D}\right) 6 \mathrm{p}^{2} \mathrm{P}_{1 / 2}^{\circ}$ & 113287 & 114068.52 & -782 & 0.74 & 0.77 & 0.96 \\
\hline $5 \mathrm{~s}^{2} 5 \mathrm{p}^{2}\left({ }^{1} \mathrm{D}\right) 5 \mathrm{~d}^{2} \mathrm{D}_{3 / 2}$ & 114014 & 111856.1 & 2158 & 0.90 & & \\
\hline $5 \mathrm{~s}^{2} 5 \mathrm{p}^{2}\left({ }^{1} \mathrm{D}\right) 5 \mathrm{~d}^{2} \mathrm{D}_{5 / 2}$ & 114884 & 113564.5 & 1320 & 1.21 & & \\
\hline $5 \mathrm{~s}^{2} 5 \mathrm{p}^{2}\left({ }^{1} \mathrm{D}\right) 6 \mathrm{p}^{2} \mathrm{P}_{3 / 2}^{\circ}$ & 115288 & 116101.71 & -814 & 1.28 & 1.29 & 1.00 \\
\hline $5 \mathrm{~s}^{2} 5 \mathrm{p}^{2}\left({ }^{1} \mathrm{~S}\right) 5 \mathrm{~d}^{2} \mathrm{D}_{3 / 2}$ & 119058 & 118325.5 & 733 & 0.80 & & \\
\hline $5 s^{2} 5 p^{2}\left({ }^{1} S\right) 5 d^{2} D_{5 / 2}$ & 119587 & 118420.6 & 1166 & 1.19 & & \\
\hline $5 \mathrm{~s} 5 \mathrm{p}^{4}\left({ }^{3} \mathrm{P}\right){ }^{2} \mathrm{P}_{1 / 2}$ & 119885 & 117192.38 & 2693 & 1.04 & & \\
\hline $5 s^{2} 5 p^{2}\left({ }^{1} S\right) 6 p^{2} P_{1 / 2}^{\circ}$ & 125147 & 126047.99 & -901 & 0.67 & 0.29 & 2.30 \\
\hline $5 s^{2} 5 p^{2}\left({ }^{1} S\right) 6 p^{2} P_{3 / 2}^{\circ}$ & 125844 & 126309.55 & -466 & 1.33 & 1.02 & 1.31 \\
\hline
\end{tabular}

Notes. ${ }^{(a)}$ Kramida et al. (2012); ${ }^{(b)} \operatorname{MCDHF}$ (this work); ${ }^{(c)} \Delta E=E_{\mathrm{DHF}}-E_{\mathrm{Exp}}$. 
A\&A 551, A136 (2013)

Table 2. Comparison between experimental and MCDHF level energies and Landé factors in Te III.

\begin{tabular}{|c|c|c|c|c|c|c|}
\hline Designation $^{a}$ & $\begin{array}{l}E_{\mathrm{DHF}}^{b} \\
\left(\mathrm{~cm}^{-1}\right)\end{array}$ & $\begin{array}{c}E_{\operatorname{Exp}^{a}} \\
\left(\mathrm{~cm}^{-1}\right)\end{array}$ & $\begin{array}{c}\Delta E^{c} \\
\left(\mathrm{~cm}^{-1}\right)\end{array}$ & $g_{\mathrm{DHF}}^{b}$ & $g_{\text {Exp }}{ }^{d}$ & $g_{\mathrm{DHF}} / g_{\mathrm{Exp}}$ \\
\hline $5 s^{2} 5 p^{2}{ }^{3} P_{0}$ & 0 & 0.0 & 0 & & & \\
\hline $5 s^{2} 5 p^{2}{ }^{3} P_{1}$ & 4401 & 4757.2 & -356 & 1.50 & & \\
\hline $5 s^{2} 5 p^{2}{ }^{3} P_{2}$ & 7824 & 8167.0 & -343 & 1.41 & & \\
\hline $5 \mathrm{~s}^{2} 5 \mathrm{p}^{2}{ }^{1} \mathrm{D}_{2}$ & 17057 & 17359.8 & -303 & 1.10 & & \\
\hline $5 s^{2} 5 p^{2}{ }^{1} S_{0}$ & 30491 & 30398.3 & 93 & & & \\
\hline $5 s 5 p^{3}\left({ }^{4} S\right){ }^{5} S_{2}^{\circ}$ & 58842 & 64586.5 & -5745 & 1.99 & & \\
\hline $5 s 5 p^{3}\left({ }^{2} D\right){ }^{3} D_{1}^{\circ}$ & 79119 & 82889.1 & -3770 & 0.56 & & \\
\hline $5 s 5 p^{3}\left({ }^{2} D\right){ }^{3} D_{2}^{\circ}$ & 79406 & 83203.4 & -3797 & 1.20 & & \\
\hline $5 \mathrm{~s} 5 \mathrm{p}^{3}\left({ }^{2} \mathrm{D}\right){ }^{3} \mathrm{D}_{3}^{\circ}$ & 81273 & 85205.6 & -3933 & 1.33 & & \\
\hline $5 \mathrm{~s} 5 \mathrm{p}^{3}\left({ }^{2} \mathrm{P}\right){ }^{3} \mathrm{P}_{2}^{\circ}$ & 92185 & 95031.3 & -2846 & 1.26 & & \\
\hline $5 \mathrm{~s} 5 \mathrm{p}^{3}\left({ }^{2} \mathrm{P}\right){ }^{3} \mathrm{P}_{0}^{\circ}$ & 92930 & 96061.6 & -3132 & & & \\
\hline $5 \mathrm{~s} 5 \mathrm{p}^{3}\left({ }^{2} \mathrm{P}\right){ }^{3} \mathrm{P}_{1}^{\circ}$ & 93431 & 96581.5 & -3151 & 1.45 & & \\
\hline $5 \mathrm{~s} 5 \mathrm{p}^{3}\left({ }^{2} \mathrm{P}\right){ }^{3} \mathrm{P}_{2}^{\circ}$ & 97488 & 100469.1 & -2981 & 1.18 & 1.13 & 1.04 \\
\hline $5 s^{2} 5 p 5 d^{3} F_{2}^{\circ}$ & 102882 & 104717.2 & -1835 & 0.72 & & \\
\hline $5 s^{2} 5 p 5 d^{3} F_{3}^{\circ}$ & 104644 & 106314.8 & -1671 & 1.09 & 1.07 & 1.02 \\
\hline $5 \mathrm{~s}^{2} 5 \mathrm{p} 6 \mathrm{~s}^{3} \mathrm{P}_{0}^{3}$ & 105878 & 107470.0 & -1592 & & & \\
\hline $5 s^{2} 5 p 6 s^{3} P_{1}^{0}$ & 106374 & 107726.6 & -1353 & 1.37 & 1.37 & 1.00 \\
\hline $5 s^{2} 5 p 5 d^{3} P_{2}^{\circ}$ & 113858 & 115422.2 & -1564 & 1.49 & 1.28 & 1.16 \\
\hline $5 \mathrm{~s}^{2} 5 \mathrm{p} 5 \mathrm{~d}^{1} \mathrm{P}_{0}^{\mathrm{o}}$ & 113901 & 114216.4 & -315 & 1.07 & 1.00 & 1.07 \\
\hline $5 \mathrm{~s}^{2} 5 \mathrm{p} 6 \mathrm{~s}^{3} \mathrm{P}_{2}^{\circ}$ & 117392 & 116719.4 & 673 & 1.34 & 1.34 & 1.00 \\
\hline $5 s^{2} 5 p 5 d^{3} D_{1}^{\circ}$ & 117444 & 115747.6 & 1696 & 0.84 & & \\
\hline $5 s^{2} 5 p 6 s{ }^{1} P_{1}^{\circ}$ & 119993 & 117796.1 & 2197 & 1.33 & 1.26 & 1.06 \\
\hline $5 s^{2} 5 p 5 d^{1} F_{3}^{\circ}$ & 121689 & 120903.4 & 786 & 1.30 & 1.35 & 0.96 \\
\hline $5 s^{2} 5 p 5 d^{3} \mathrm{P}_{0}^{\circ}$ & 122998 & 122541.0 & 457 & & & \\
\hline $5 s^{2} 5 p 5 d^{3} P_{1}^{0}$ & 123047 & 122127.4 & 920 & 1.24 & & \\
\hline $5 s^{2} 5 p 5 d^{3} D_{2}^{\circ}$ & 123476 & 122515.0 & 961 & 1.29 & & \\
\hline $5 \mathrm{~s}^{2} 5 \mathrm{p} 5 \mathrm{~d}^{3} \mathrm{P}_{1}^{\circ}$ & 126627 & 124787.9 & 1839 & 1.62 & & \\
\hline $5 s^{2} 5 p 6 p^{3} D_{1}$ & 126865 & 128617.9 & -1753 & 0.72 & 0.68 & 1.06 \\
\hline $5 s^{2} 5 p 5 d^{3} F_{3}^{\circ}$ & 128502 & 127242.3 & 1260 & 1.03 & & \\
\hline $5 \mathrm{~s}^{2} 5 \mathrm{p} 6 \mathrm{p}^{3} \mathrm{P}_{1}^{\circ}$ & 130258 & 132116.7 & -1859 & 1.27 & 1.24 & 1.03 \\
\hline $5 \mathrm{~s} 5 \mathrm{p}^{3}\left({ }^{2} \mathrm{D}\right){ }^{1} \mathrm{D}_{2}^{\circ}$ & 130315 & 127188.8 & 3126 & 1.04 & & \\
\hline $5 s^{2} 5 p 6 p^{3} P_{0}$ & 130575 & 132262.4 & -1687 & & & \\
\hline $5 s^{2} 5 p 6 p^{3} D_{2}$ & 130598 & 132329.1 & -1731 & 1.19 & 1.16 & 1.03 \\
\hline $5 \mathrm{~s}^{2} 5 \mathrm{p} 6 \mathrm{p}{ }^{1} \mathrm{P}_{1}$ & 136083 & 138289.7 & -2207 & 1.14 & 1.02 & 1.12 \\
\hline $5 s^{2} 5 p 6 p^{3} P_{2}$ & 137599 & 139664.5 & -2066 & 1.36 & 1.43 & 0.95 \\
\hline $5 s^{2} 5 p 6 p^{3} D_{3}$ & 138061 & 139949.7 & -1889 & 1.33 & 1.28 & 1.04 \\
\hline $5 s^{2} 5 p 6 p^{3} S_{1}$ & 139694 & 141803.0 & -2109 & 1.87 & 1.76 & 1.06 \\
\hline $5 \mathrm{~s} 5 \mathrm{p}^{3}\left({ }^{2} \mathrm{P}\right){ }^{1} \mathrm{P}_{1}^{\circ}$ & 139847 & 136476.2 & 3371 & 1.03 & & \\
\hline $5 \mathrm{~s}^{2} 5 \mathrm{p} 6 \mathrm{p}^{1} \mathrm{D}_{2}$ & 141021 & 142982.0 & -1961 & 1.12 & 1.14 & 0.98 \\
\hline
\end{tabular}

Notes. ${ }^{(a)}$ Tauheed \& Naz (2011). 5p6p levels are from Kramida et al. (2012). The first component of the LS composition by Tauheed \& Naz (2011) is taken as the designation. ${ }^{(b)} \mathrm{MCDHF}$ (this work). ${ }^{(c)} \Delta E=E_{\mathrm{DHF}}-E_{\mathrm{Exp}} .{ }^{\left({ }^{(d)}\right.}$ Kramida et al. (2012).

The final MCDHF electric dipole (E1) transition probabilities have been corrected using the experimental energies as follows:

$A_{k i}^{\mathrm{cor}}=\left(\frac{E_{k}^{\mathrm{exp}}-E_{i}^{\mathrm{exp}}}{E_{k}^{\mathrm{DHF}}-E_{i}^{\mathrm{DHF}}}\right)^{3} A_{k i}^{\mathrm{DHF}}$

where $A_{k i}^{\text {cor }}$ and $A_{k i}^{\mathrm{DHF}}$ are respectively the corrected and MCDHF transition probability of the E1 transition between the upper level $k$ and the lower level $i$, and $E_{k(i)}^{\exp }$ and $E_{k(i)}^{\mathrm{DHF}}$ are respectively the experimental and the MCDHF upper (lower) level energy.

These $A$-values have been determined in the Babushkin and Coulomb gauges, the equivalents of the length and velocity gauges in the non-relativistic limit. A good agreement between these values is a necessary condition for an accurate estimate of the line strength, though it is still not a sufficient condition. We have therefore considered an additional and independent criteria to estimate this accuracy; we have modified the GRASP2K package (Jonsson et al. 2007) to include the calculation of the cancellation factor (CF) as defined by Cowan (1981), i.e.:

$C F=\left(\frac{\left|\sum_{k} \sum_{i} c_{k}^{\prime}<\Phi^{\prime}\left(\alpha_{k} J M_{J}\right)\right| D^{(1)}\left|\Phi\left(\alpha_{i} J M_{J}\right)>c_{i}\right|}{\sum_{i} \sum_{k}\left|c_{k}^{\prime}<\Phi^{\prime}\left(\alpha_{k} J M_{J}\right)\right| D^{(1)}\left|\Phi\left(\alpha_{i} J M_{J}\right)>c_{i}\right|}\right)^{2}$

where $D^{(1)}$ is the electric dipole operator and $c_{i(k)}\left({ }^{\prime}\right)$ and $\Phi\left(^{\prime}\right)\left(\alpha_{i(k)} J M_{J}\right)$ have the same meanings as in Eq. (1) for the initial (non-primed symbols) and final (primed symbols) states of the transition. A small value of the cancellation factor (say less than 0.05) indicates that the calculated line strength is affected by a strong cancellation effect; this is due to opposite sign contributions of almost equal and significant amplitudes that cancel each other in the transition amplitude expansions which are directly related to the ASF representation (here, in $j j$ coupling). Table 3 illustrates in Te II the complementarity of the gauges agreement criteria and the cancellation factor in the four possible cases, i.e. bad gauges agreement (agreement $>10 \%$ ) and small 
W. Zhang et al.: Transition probabilities in Te II and Te III spectra

Table 3. Illustration in Te II of the complementarity between the criteria of the gauges agreement and the cancellation factor in the estimation of the $A$-value accuracy in the four possible cases.

\begin{tabular}{lrrrrr}
\hline \hline \multirow{2}{*}{ Transition } & \multicolumn{2}{c}{ MCDHF } & \multicolumn{2}{c}{ HFR+CPOL } \\
& $g A_{B}\left(\mathrm{~s}^{-1}\right)^{a}$ & $\mathrm{C}^{b} \mathrm{~B}^{b}$ & $C F$ & $g A\left(\mathrm{~s}^{-1}\right)$ & $C F$ \\
\hline $5 \mathrm{~s}^{2} 5 \mathrm{p}^{3}{ }^{4} \mathrm{~S}_{3 / 2}^{\circ}-5 \mathrm{~s}^{2} 5 \mathrm{p}^{2}\left({ }^{1} \mathrm{D}\right) 5 \mathrm{~d}^{2} \mathrm{~F}_{5 / 2}$ & $2.29(+6)$ & 0.66 & $2(-5)$ & $6.51(+7)$ & $6(-3)$ \\
$5 \mathrm{~s}^{2} 5 \mathrm{p}^{2}\left({ }^{1} \mathrm{D}\right) 5 \mathrm{~d}^{2} \mathrm{~S}_{1 / 2}-5 \mathrm{~s}^{2} 5 \mathrm{p}^{2}\left({ }^{1} \mathrm{D}\right) 6 \mathrm{p}^{2} \mathrm{P}_{1 / 2}^{\circ}$ & $2.70(+7)$ & 0.56 & 0.15 & $6.15(+6)$ & 0.22 \\
$5 \mathrm{~s}^{2} 5 \mathrm{p}^{2}\left({ }^{3} \mathrm{P}\right) 5 \mathrm{~d}^{2} \mathrm{P}_{1 / 2}-5 \mathrm{~s}^{2} 5 \mathrm{p}^{2}\left({ }^{3} \mathrm{P}\right) 6 \mathrm{p}^{2} \mathrm{~S}_{1 / 2}^{\circ}$ & $1.60(+6)$ & 1.04 & 0.04 & $1.83(+6)$ & 0.08 \\
$5 \mathrm{~s}^{2} 5 \mathrm{p}^{2}\left({ }^{3} \mathrm{P}\right) 6 \mathrm{~s}^{4} \mathrm{P}_{1 / 2}-5 \mathrm{~s}^{2} 5 \mathrm{p}^{2}\left({ }^{3} \mathrm{P}\right) 6 \mathrm{p}^{4} \mathrm{D}_{3 / 2}^{\circ}$ & $3.29(+8)$ & 0.96 & 0.63 & $3.06(+8)$ & 0.64 \\
\hline
\end{tabular}

Notes. Only the last transition is to be retained in the MCDHF calculation. The corresponding HFR+CPOL transition probabilities and $C F$ values are listed for comparison. ${ }^{(a)}$ Babushkin gauge corrected using the experimental level energies. ${ }^{(b)}$ Coulomb to Babushkin ratio. $A(B)$ stands for $A \times 10^{B}$.

$C F(<0.05)$, bad gauges agreement and $C F>0.05$, good gauges agreement (agreement $<10 \%$ ) and small $C F$, and good gauges agreement and $C F>0.05$; only the last case is indicative of an accurate MCDHF $A$-value. The corresponding HFR+CPOL transition probabilities and $C F$ values have been also included for comparison.

\subsection{Relativistic Hartree-Fock (HFR)}

The relativistic Hartree-Fock (HFR) approach including corepolarization (CPOL) effects by means of a model potential and a correction to the transition dipole operator (HFR + CPOL) have been used to investigate the transition probabilities of Te II and Te III.

For Te II, 43 configurations: $5 \mathrm{p}^{3}+5 \mathrm{p}^{2} 6 \mathrm{p}+5 \mathrm{p}^{2} 7 \mathrm{p}+$ $5 \mathrm{p}^{2} 4 \mathrm{f}+5 \mathrm{p}^{2} 5 \mathrm{f}+5 \mathrm{p}^{2} 6 \mathrm{f}+5 \mathrm{~d}^{2} 6 \mathrm{p}+5 \mathrm{~d}^{2} 6 \mathrm{f}+6 \mathrm{~s}^{2} 7 \mathrm{p}+5 \mathrm{~d}^{2} 7 \mathrm{p}+$ $4 \mathrm{f}^{2} 5 \mathrm{p}+5 \mathrm{f}^{2} 6 \mathrm{p}+5 \mathrm{~s} 5 \mathrm{p}^{3} 6 \mathrm{~s}+5 \mathrm{~s} 5 \mathrm{p}^{3} 5 \mathrm{~d}+5 \mathrm{~s} 5 \mathrm{p}^{3} 6 \mathrm{~d}+5 \mathrm{~s} 5 \mathrm{p}^{2} 6 \mathrm{p} 5 \mathrm{~d}+$ $5 \mathrm{~s} 5 \mathrm{p}^{2} 6 \mathrm{p} 6 \mathrm{~d}+5 \mathrm{~s} 5 \mathrm{p}^{2} 4 \mathrm{f} 5 \mathrm{~d}+5 \mathrm{~s} 5 \mathrm{p}^{2} 4 \mathrm{f} 6 \mathrm{~d}+5 \mathrm{p}^{5}$ (odd parity) and $5 \mathrm{~s} 5 \mathrm{p}^{4}+5 \mathrm{p}^{2} 5 \mathrm{~d}+5 \mathrm{p}^{2} 6 \mathrm{~d}+5 \mathrm{p}^{2} 7 \mathrm{~d}+5 \mathrm{p}^{2} 6 \mathrm{~d}+5 \mathrm{p}^{2} 7 \mathrm{~d}+5 \mathrm{p}^{2} 6 \mathrm{~s}+$ $5 \mathrm{p}^{2} 7 \mathrm{~s}+5 \mathrm{p}^{2} 8 \mathrm{~s}+5 \mathrm{p}^{2} 5 \mathrm{~g}+5 \mathrm{p}^{2} 6 \mathrm{~g}+5 \mathrm{~d}^{2} 5 \mathrm{~g}+5 \mathrm{~d}^{2} 6 \mathrm{~g}+5 \mathrm{f}^{2} 5 \mathrm{~g}+$ $5 \mathrm{f}^{2} 6 \mathrm{~g}+5 \mathrm{~s} 5 \mathrm{p}^{3} 6 \mathrm{p}+5 \mathrm{~s} 5 \mathrm{p}^{3} 4 \mathrm{f}+5 \mathrm{~s} 5 \mathrm{p}^{3} 5 \mathrm{f}+5 \mathrm{~s} 5 \mathrm{p}^{3} 6 \mathrm{f}+5 \mathrm{~s} 5 \mathrm{p}^{2} 6 \mathrm{~s} 5 \mathrm{~d}+$ $5 s 5 p^{2} 6 s 6 d+5 s 5 p^{2} 5 d 6 d+5 s 5 p^{2} 6 s^{2}+5 s 5 p^{2} 5 d^{2}$ (even parity) have been considered.

For Te III, 48 configurations: $5 \mathrm{p}^{2}+5 \mathrm{p} 6 \mathrm{p}+5 \mathrm{p} 7 \mathrm{p}+5 \mathrm{p} 4 \mathrm{f}+$ $5 \mathrm{p} 5 \mathrm{f}+5 \mathrm{p} 6 \mathrm{f}+5 \mathrm{~d} 6 \mathrm{~s}+5 \mathrm{~d} 6 \mathrm{~d}+6 \mathrm{~s}^{2}+5 \mathrm{~d}^{2}+4 \mathrm{f}^{2}+5 \mathrm{f}^{2}+$ $5 \mathrm{~s} 5 \mathrm{p}^{2} 6 \mathrm{~s}+5 \mathrm{~s} 5 \mathrm{p}^{2} 5 \mathrm{~d}+5 \mathrm{~s} 5 \mathrm{p}^{2} 6 \mathrm{~d}+5 \mathrm{~s} 5 \mathrm{p} 6 \mathrm{~s} 6 \mathrm{p}+5 \mathrm{~s} 5 \mathrm{p} 6 \mathrm{p} 5 \mathrm{~d}+$ $5 \mathrm{~s} 5 \mathrm{p} 6 \mathrm{p} 6 \mathrm{~d}+5 \mathrm{~s} 5 \mathrm{p} 4 \mathrm{f} 5 \mathrm{~d}+5 \mathrm{~s} 5 \mathrm{p} 4 \mathrm{f} 6 \mathrm{~d}+5 \mathrm{p}^{4}+5 \mathrm{p}^{3} 4 \mathrm{f}+5 \mathrm{p}^{3} 5 \mathrm{f}+$ $5 \mathrm{p}^{3} 6 \mathrm{f}$ (even parity) and $5 \mathrm{~s} 5 \mathrm{p}^{3}+5 \mathrm{p} 5 \mathrm{~d}+5 \mathrm{p} 6 \mathrm{~d}+5 \mathrm{p} 7 \mathrm{~d}+$ $5 \mathrm{p} 6 \mathrm{~s}+5 \mathrm{p} 7 \mathrm{~s}+5 \mathrm{p} 8 \mathrm{~s}+5 \mathrm{p} 5 \mathrm{~g}+5 \mathrm{p} 6 \mathrm{~g}+5 \mathrm{~d} 6 \mathrm{p}+5 \mathrm{~d} 4 \mathrm{f}+5 \mathrm{~d} 5 \mathrm{f}+$ $5 \mathrm{~d} 6 \mathrm{f}+5 \mathrm{~s} 5 \mathrm{p}^{2} 6 \mathrm{p}+5 \mathrm{~s} 5 \mathrm{p}^{2} 4 \mathrm{f}+5 \mathrm{~s} 5 \mathrm{p}^{2} 5 \mathrm{f}+5 \mathrm{~s} 5 \mathrm{p}^{2} 6 \mathrm{f}+5 \mathrm{~s} 5 \mathrm{p} 6 \mathrm{~s} 5 \mathrm{~d}+$ $5 \mathrm{~s} 5 \mathrm{p} 6 \mathrm{~s} 6 \mathrm{~d}+5 \mathrm{~s} 5 \mathrm{p} 5 \mathrm{~d} 6 \mathrm{~d}+5 \mathrm{~s} 5 \mathrm{p} 6 \mathrm{~s}^{2}+5 \mathrm{~s} 5 \mathrm{p} 5 \mathrm{~d}^{2}+5 \mathrm{p}^{3} 6 \mathrm{~s}+5 \mathrm{p}^{3} 5 \mathrm{~d}+$ $5 \mathrm{p}^{3} 6 \mathrm{~d}$ (odd parity) were included in the calculations.

In order to consider the CPOL corrections in Te II and Te III calculations, a dipole polarizability of $\alpha_{\mathrm{d}}=1.295 a_{0}^{3}$ and a cut-off radius of $r_{\mathrm{c}}=0.964 a_{0}$ were adopted. Some radial integrals, considered as free parameters, were then adjusted with a least-squares optimization program minimizing the discrepancies between the calculated Hamiltonian eigenvalues and the experimental energy levels. More precisely, the average energies $\left(E_{\mathrm{av}}\right)$, the electrostatic direct $\left(F^{k}\right)$ and exchange $\left(G^{k}\right)$ integrals, the spin-orbit $\left(\zeta_{n l}\right)$ and effective interaction $(\alpha)$ parameters were allowed to vary during the fitting process. The scaling factors, i.e. the ratios between the fitted and the HFR values (LSF/HFR), of the optimized parameters ranged between 0.61 to $1.04,0.50$ to 1.19 and 0.85 to 1.19 for, respectively, the $F^{k}, G^{k}$ and $\zeta_{n l}$ integrals in Te II. In Te III, these scaling factors became $0.72 \leq \operatorname{LSF} / \operatorname{HFR}\left(F^{k}\right) \leq 0.93,0.62 \leq \operatorname{LSF} / \operatorname{HFR}\left(G^{k}\right) \leq 0.95$ and $0.86 \leq \operatorname{LSF} / \operatorname{HFR}\left(\zeta_{n l}\right) \leq 1.27$.

For Te II, the energy levels calculated with the HFR+CPOL method are compared to available experimental values in
Tables 4 (odd levels) and 5 (even levels), the mean deviations of the fits being found equal to $217 \mathrm{~cm}^{-1}$ ( 81 levels, 36 parameters) for the even parity and $87 \mathrm{~cm}^{-1}$ (45 levels, 19 parameters) for the odd parity. For Te III, the results of the energy levels are included in Tables 6 (even levels) and 7 (odd levels), the mean deviations reaching 100 and $126 \mathrm{~cm}^{-1}$ for even and odd parity (for the even parity, 14 levels, 9 parameters; for the odd parity, 55 levels, 27 parameters), respectively. The lowest unknown energy levels, i.e. $5 \mathrm{~s}^{2} 5 \mathrm{p}^{2}\left({ }^{1} \mathrm{D}\right) 5 \mathrm{~d}^{2} \mathrm{G}_{9 / 2}$ in Te II and $5 \mathrm{~s}^{2} 5 \mathrm{p} 5 \mathrm{~d}^{3} \mathrm{~F}_{4}^{\mathrm{o}}$ in Te III, are also given in Tables 5 and 7.

The weighted oscillator strengths $(\log g f)$ and transition probabilities $(g A)$ (HFR + CPOL calculations) are reported in Tables 8 (Te II) and 9 (Te III). The electric dipole (E1) transitions between the levels reported in Tables 5-7 with wavelengths less than 1 micrometer and with cancellation factors greater than 0.05 have been selected. In Te II, the list of reported transitions has been further limited to those having a $\log g f>-1$. No limit in log gf has been set in Te III. This represents a total number of 439 transitions for Te II and 284 for Te III. Some of these transitions are emitted from high energy levels $(>8 \mathrm{eV})$ and have no chance to be observed in astrophysics. Nevertheless, they are kept in the tables for completion. There are no other (experimental or theoretical) transition probabilities available for comparison.

A majority of the calculated energy levels of Te II obtained with the HFR + CPOL method are strongly mixed, the average LS-purities being equal to $56 \%$ and $53 \%$ for the odd and even parities, respectively. For Te III, many calculated energy levels are strongly mixed and the average LS-purities of the calculated energy levels obtained by the HFR + CPOL method are equal to $74 \%$ and $65 \%$ for the even and odd parities, respectively. According to our level LS-compositions in Te III, those given in Tauheed \& Naz (2011) should be swapped between the odd levels with $J=2$ located at $115422.2 \mathrm{~cm}^{-1}$ and at $116719.4 \mathrm{~cm}^{-1}$, and between the odd levels with $J=3$ located at $120903.4 \mathrm{~cm}^{-1}$ and at $127242.3 \mathrm{~cm}^{-1}$. Moreover, the first LS-component of the odd levels with $J=3$ situated at $120903.4 \mathrm{~cm}^{-1}$ is $5 \mathrm{~s}^{2} 5 \mathrm{p} 5 \mathrm{~d}^{3} \mathrm{D}_{3}^{\mathrm{o}}$ and not $5 \mathrm{~s}^{2} 5 \mathrm{p} 5 \mathrm{~d}^{3} \mathrm{~F}_{3}^{\mathrm{o}}$ as this last spectroscopic term appears twice with purities close to $90 \%$ in the matrix $J=3$ given in the Table 2 of Tauheed \& Naz (2011); this was actually a typo as the correct designation was already given in Joshi et al. (1992). Concerning the swapping of designations between the two above-mentioned $J=2$ odd levels, although there is an agreement between Tauheed \& Naz (2011) and Joshi et al. (1992), our HFR+CPOL designations agree with the NIST database (Kramida et al. 2012) and there is a consistancy with our MCDHF, HFR+CPOL and the experimental Landé $g$ factors (we took the Tauheed \& Naz (2011) designations in Table 2 as our MCDHF calculation is in $j j$-coupling 
Table 4. Comparison between experimental and HFR+CPOL level energies and Landé factors in Te II (odd levels).

\begin{tabular}{|c|c|c|c|c|c|}
\hline$E_{\operatorname{Exp}}{ }^{a}\left(\mathrm{~cm}^{-1}\right)$ & $E_{\mathrm{Calc}}^{b}\left(\mathrm{~cm}^{-1}\right)$ & $g_{\text {Calc }}^{b}$ & $g_{\mathrm{Exp}}{ }^{a}$ & $g_{\text {Calc }} / g_{\text {Exp }}$ & LS-composition $^{b}$ \\
\hline \multicolumn{6}{|l|}{$J=1 / 2$} \\
\hline 20546.591 & 20566 & 0.67 & & & $96.8 \% 5 \mathrm{~s}^{2} 5 \mathrm{p}^{32} \mathrm{P}^{\circ}+1.6 \% 5 \mathrm{p}^{52} \mathrm{P}^{\circ}$ \\
\hline 93978.93 & 94001 & 0.80 & 0.79 & 1.01 & $49.5 \% 5 p^{2}\left({ }^{3} \mathrm{P}\right) 6 \mathrm{p}^{4} \mathrm{D}^{\circ}+21.0 \% 5 \mathrm{p}^{2}\left({ }^{3} \mathrm{P}\right) 6 \mathrm{p}^{2} \mathrm{~S}^{\circ}$ \\
\hline 97780.09 & 97809 & 1.26 & 1.26 & 1.00 & $48.6 \% 5 \mathrm{p}^{2}\left({ }^{3} \mathrm{P}\right) 6 \mathrm{p}^{2} \mathrm{~S}^{\circ}+38.0 \% 5 \mathrm{p}^{2}\left({ }^{3} \mathrm{P}\right) 6 \mathrm{p}{ }^{4} \mathrm{D}^{\circ}$ \\
\hline 101370.86 & 101204 & 2.33 & 2.33 & 1.00 & $74.8 \% 5 \mathrm{p}^{2}\left({ }^{3} \mathrm{P}\right) 6 \mathrm{p}^{4} \mathrm{P}^{\circ}+10.1 \% 5 \mathrm{p}^{2}\left({ }^{3} \mathrm{P}\right) 6 \mathrm{p}^{2} \mathrm{P}^{\circ}$ \\
\hline 106119.20 & 106214 & 0.85 & 0.87 & 0.98 & $71.4 \% 5 \mathrm{p}^{2}\left({ }^{3} \mathrm{P}\right) 6 \mathrm{p}^{2} \mathrm{P}^{\circ}+11.9 \% 5 \mathrm{p}^{2}\left({ }^{3} \mathrm{P}\right) 6 \mathrm{p}^{2} \mathrm{~S}^{\circ}$ \\
\hline 114068.52 & 113939 & 0.76 & 0.77 & 0.98 & $86.3 \% 5 \mathrm{p}^{2}\left({ }^{1} \mathrm{D}\right) 6 \mathrm{p}{ }^{2} \mathrm{P}^{\circ}+5.0 \% 5 \mathrm{p}^{2}\left({ }^{3} \mathrm{P}\right) 6 \mathrm{p}^{2} \mathrm{~S}^{\circ}$ \\
\hline 125287.32 & 125295 & 0.84 & 0.86 & 0.98 & $25.7 \% 5 \mathrm{p}^{2}\left({ }^{1} \mathrm{~S}\right) 6 \mathrm{p}^{2} \mathrm{P}^{\circ}+32.3 \% 5 \mathrm{p}^{2}\left({ }^{3} \mathrm{P}\right) 4 \mathrm{f}^{4} \mathrm{D}^{\circ}$ \\
\hline 126047.99 & 126080 & 0.53 & 0.29 & 1.83 & $46.9 \% 5 \mathrm{p}^{2}\left({ }^{3} \mathrm{P}\right) 4 \mathrm{f}^{4} \mathrm{D}^{\circ}+31.9 \% 5 \mathrm{p}^{2}\left({ }^{1} \mathrm{~S}\right) 6 \mathrm{p}^{2} \mathrm{P}^{\circ}$ \\
\hline \multicolumn{6}{|r|}{ 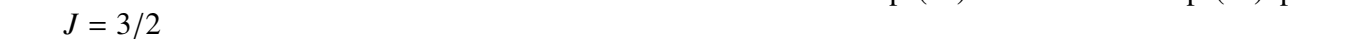 } \\
\hline 0.000 & 2 & 1.94 & 1.93 & 1.01 & $89.9 \% 5 \mathrm{~s}^{2} 5 \mathrm{p}^{3}{ }^{4} \mathrm{~S}^{\circ}+6.4 \% 5 \mathrm{~s}^{2} 5 \mathrm{p}^{3}{ }^{2} \mathrm{P}^{\circ}$ \\
\hline 10222.385 & 10185 & 0.93 & & & $79.4 \% 5 \mathrm{~s}^{2} 5 \mathrm{p}^{32} \mathrm{D}^{\circ}+13.9 \% 5 \mathrm{~s}^{2} 5 \mathrm{p}^{3}{ }^{2} \mathrm{P}^{\circ}$ \\
\hline 24032.095 & 24014 & 1.27 & 1.27 & 1.00 & $76.5 \% 5 \mathrm{~s}^{2} 5 \mathrm{p}^{32} \mathrm{P}^{\circ}+16.8 \% 5 \mathrm{~s}^{2} 5 \mathrm{p}^{32} \mathrm{D}^{\circ}$ \\
\hline 96144.74 & 96138 & 1.34 & 1.32 & 1.02 & $48.8 \% 5 \mathrm{p}^{2}\left({ }^{3} \mathrm{P}\right) 6 \mathrm{p}^{4} \mathrm{D}^{\circ}+22.1 \% 5 \mathrm{p}^{2}\left({ }^{3} \mathrm{P}\right) 6 \mathrm{p}^{4} \mathrm{P}^{\circ}$ \\
\hline 99584.59 & 99618 & 1.32 & 1.26 & 1.05 & $41.3 \% 5 \mathrm{p}^{2}\left({ }^{3} \mathrm{P}\right) 6 \mathrm{p}^{4} \mathrm{D}^{\circ}+16.2 \% 5 \mathrm{p}^{2}\left({ }^{3} \mathrm{P}\right) 6 \mathrm{p}^{2} \mathrm{D}^{\circ}$ \\
\hline 101220.97 & 101295 & 1.24 & 1.31 & 0.94 & $51.8 \% 5 \mathrm{p}^{2}\left({ }^{3} \mathrm{P}\right) 6 \mathrm{p}^{2} \mathrm{D}^{\circ}+27.5 \% 5 \mathrm{p}^{2}\left({ }^{3} \mathrm{P}\right) 6 \mathrm{p}^{4} \mathrm{~S}^{\circ}$ \\
\hline 103935.90 & 103702 & 1.73 & 1.74 & 0.99 & $41.6 \% 5 \mathrm{p}^{2}\left({ }^{3} \mathrm{P}\right) 6 \mathrm{p}^{4} \mathrm{P}^{\circ}+36.3 \% 5 \mathrm{p}^{2}\left({ }^{3} \mathrm{P}\right) 6 \mathrm{p}{ }^{4} \mathrm{~S}^{\circ}$ \\
\hline 105006.08 & 105021 & 1.21 & 1.21 & 1.00 & $60.9 \% 5 \mathrm{p}^{2}\left({ }^{3} \mathrm{P}\right) 6 \mathrm{p}^{2} \mathrm{P}^{\circ}+24.8 \% 5 \mathrm{p}^{2}\left({ }^{1} \mathrm{D}\right) 6 \mathrm{p}^{2} \mathrm{D}^{\circ}$ \\
\hline 112272.43 & 112161 & 1.09 & 1.09 & 1.00 & $45.1 \% 5 \mathrm{p}^{2}\left({ }^{1} \mathrm{D}\right) 6 \mathrm{p}^{2} \mathrm{D}^{\circ}+24.4 \% 5 \mathrm{p}^{2}\left({ }^{1} \mathrm{D}\right) 6 \mathrm{p}^{2} \mathrm{P}^{\circ}$ \\
\hline 116101.71 & 116022 & 1.28 & 1.29 & 0.99 & $49.3 \% 5 \mathrm{p}^{2}\left({ }^{1} \mathrm{D}\right) 6 \mathrm{p}^{2} \mathrm{P}^{\circ}+20.4 \% 5 \mathrm{p}^{2}\left({ }^{3} \mathrm{P}\right) 6 \mathrm{p}^{2} \mathrm{P}^{\circ}$ \\
\hline 122775.20 & 122749 & 0.72 & 0.71 & 1.01 & $46.7 \% 5 \mathrm{p}^{2}\left({ }^{3} \mathrm{P}\right) 4 \mathrm{f}^{4} \mathrm{~F}^{\circ}+25.1 \% 5 \mathrm{p}^{2}\left({ }^{3} \mathrm{P}\right) 4 \mathrm{f}^{4} \mathrm{D}^{\circ}$ \\
\hline 125442.46 & 125337 & 1.21 & 1.21 & 1.00 & $29.7 \% 5 \mathrm{p}^{2}\left({ }^{1} \mathrm{~S}\right) 6 \mathrm{p}^{2} \mathrm{P}^{\circ}+24.4 \% 5 \mathrm{p}^{2}\left({ }^{3} \mathrm{P}\right) 4 \mathrm{f}^{4} \mathrm{D}^{\circ}$ \\
\hline 126138.35 & 126087 & 0.87 & 0.91 & 0.96 & $31.9 \% 5 \mathrm{p}^{2}\left({ }^{3} \mathrm{P}\right) 4 \mathrm{f}^{4} \mathrm{~F}^{\circ}+26.4 \% 5 \mathrm{p}^{2}\left({ }^{3} \mathrm{P}\right) 4 \mathrm{f}^{4} \mathrm{D}^{\circ}$ \\
\hline $\begin{array}{r}126309.55 \\
J=5 / 2\end{array}$ & 126374 & 1.06 & 1.02 & 1.04 & $35.3 \% 5 \mathrm{p}^{2}\left({ }^{3} \mathrm{P}\right) 4 \mathrm{f}^{2} \mathrm{D}^{\circ}+34.6 \% 5 \mathrm{p}^{2}\left({ }^{1} \mathrm{~S}\right) 6 \mathrm{p}^{2} \mathrm{P}^{\circ}$ \\
\hline 12421.854 & 12455 & 1.20 & & & $97.4 \% 5 \mathrm{~s}^{2} 5 \mathrm{p}^{32} \mathrm{D}^{\circ}+0.8 \% 5 \mathrm{~s} 5 \mathrm{p}^{3} 5 \mathrm{~d}^{2} \mathrm{D}^{\circ}$ \\
\hline 100112.10 & 100114 & 1.40 & 1.40 & 1.00 & $76.9 \% 5 \mathrm{p}^{2}\left({ }^{3} \mathrm{P}\right) 6 \mathrm{p}^{4} \mathrm{D}^{\circ}+15.0 \% 5 \mathrm{p}^{2}\left({ }^{3} \mathrm{P}\right) 6 \mathrm{p}^{4} \mathrm{P}^{\circ}$ \\
\hline 102324.49 & 102316 & 1.33 & 1.31 & 1.03 & $34.3 \% 5 \mathrm{p}^{2}\left({ }^{3} \mathrm{P}\right) 6 \mathrm{p}^{4} \mathrm{P}^{\circ}+23.5 \% 5 \mathrm{p}^{2}\left({ }^{3} \mathrm{P}\right) 6 \mathrm{p}^{2} \mathrm{D}^{\circ}$ \\
\hline 105583.02 & 105731 & 1.27 & 1.29 & 0.98 & $45.4 \% 5 \mathrm{p}^{2}\left({ }^{3} \mathrm{P}\right) 6 \mathrm{p}^{2} \mathrm{D}^{\circ}+29.3 \% 5 \mathrm{p}^{2}\left({ }^{3} \mathrm{P}\right) 6 \mathrm{p}^{4} \mathrm{P}^{\circ}$ \\
\hline 111946.69 & 111831 & 1.23 & 1.19 & 1.04 & $63.6 \% 5 \mathrm{p}^{2}\left({ }^{1} \mathrm{D}\right) 6 \mathrm{p}^{2} \mathrm{D}^{\circ}+17.9 \% 5 \mathrm{p}^{2}\left({ }^{3} \mathrm{P}\right) 6 \mathrm{p}^{4} \mathrm{P}^{\circ}$ \\
\hline 112548.84 & 112770 & 1.01 & 1.06 & 0.95 & $58.8 \% 5 \mathrm{p}^{2}\left({ }^{1} \mathrm{D}\right) 6 \mathrm{p}^{2} \mathrm{~F}+22.4 \% 5 \mathrm{p}^{2}\left({ }^{3} \mathrm{P}\right) 6 \mathrm{p}^{2} \mathrm{D}$ \\
\hline 117685.83 & 117721 & 0.84 & 0.85 & 0.99 & $46.0 \% 5 \mathrm{p}^{2}\left({ }^{3} \mathrm{P}\right) 4 \mathrm{f}^{4} \mathrm{G}^{\circ}+17.8 \% 5 \mathrm{p}^{2}\left({ }^{3} \mathrm{P}\right) 4 \mathrm{f}^{2} \mathrm{D}^{\circ}$ \\
\hline 122027.77 & 121975 & 0.95 & 0.95 & 1.00 & $41.2 \% 5 \mathrm{p}^{2}\left({ }^{3} \mathrm{P}\right) 4 \mathrm{f}^{4} \mathrm{G}^{\circ}+38.8 \% 5 \mathrm{p}^{2}\left({ }^{3} \mathrm{P}\right) 4 \mathrm{f}^{2} \mathrm{D}^{\circ}$ \\
\hline 122887.62 & 122871 & 1.18 & 1.16 & 1.02 & $38.4 \% 5 \mathrm{p}^{2}\left({ }^{3} \mathrm{P}\right) 4 \mathrm{f}^{4} \mathrm{D}^{\circ}+18.8 \% 5 \mathrm{p}^{2}\left({ }^{3} \mathrm{P}\right) 4 \mathrm{f}^{2} \mathrm{~F}^{\circ}$ \\
\hline 123885.43 & 123890 & 1.40 & 1.38 & 1.01 & $62.8 \% 5 \mathrm{p}^{2}\left({ }^{3} \mathrm{P}\right) 7 \mathrm{p}^{4} \mathrm{D}^{\circ}+22.9 \% 5 \mathrm{p}^{2}\left({ }^{3} \mathrm{P}\right) 7 \mathrm{p}^{4} \mathrm{P}^{\circ}$ \\
\hline 126063.01 & 125955 & 1.10 & 1.11 & 0.99 & $45.7 \% 5 \mathrm{p}^{2}\left({ }^{3} \mathrm{P}\right) 4 \mathrm{f}^{4} \mathrm{~F}^{\circ}+23.4 \% 5 \mathrm{p}^{2}\left({ }^{3} \mathrm{P}\right) 4 \mathrm{f}^{4} \mathrm{D}^{\circ}$ \\
\hline 126219.97 & 126287 & 0.94 & 0.97 & 0.97 & $51.7 \% 5 \mathrm{p}^{2}\left({ }^{3} \mathrm{P}\right) 4 \mathrm{f}^{2} \mathrm{~F}^{\circ}+17.3 \% 5 \mathrm{p}^{2}\left({ }^{1} \mathrm{D}\right) 4 \mathrm{f}^{2} \mathrm{~F}^{\circ}$ \\
\hline $\begin{array}{r}135403.3 \\
J=7 / 2\end{array}$ & 135471 & 1.18 & & & $70.9 \% 5 \mathrm{p}^{2}\left({ }^{1} \mathrm{D}\right) 4 \mathrm{f}^{2} \mathrm{D}^{\circ}+9.3 \% 5 \mathrm{p}^{2}\left({ }^{3} \mathrm{P}\right) 4 \mathrm{f}^{4} \mathrm{D}^{\circ}$ \\
\hline 103105.86 & 103111 & 1.38 & 1.38 & 1.00 & $79.9 \% 5 \mathrm{p}^{2}\left({ }^{3} \mathrm{P}\right) 6 \mathrm{p}^{4} \mathrm{D}^{\circ}+16.6 \% 5 \mathrm{p}^{2}\left({ }^{1} \mathrm{D}\right) 6 \mathrm{p}^{2} \mathrm{~F}^{\circ}$ \\
\hline 112788.49 & 112998 & 1.19 & 1.20 & 0.99 & $80.3 \% 5 \mathrm{p}^{2}\left({ }^{1} \mathrm{D}\right) 6 \mathrm{p}^{2} \mathrm{~F}^{\circ}+16.2 \% 5 \mathrm{p}^{2}\left({ }^{3} \mathrm{P}\right) 6 \mathrm{p}^{4} \mathrm{D}^{\circ}$ \\
\hline 117859.06 & 117892 & 1.15 & 1.13 & 1.02 & $26.4 \% 5 \mathrm{p}^{2}\left({ }^{3} \mathrm{P}\right) 4 \mathrm{f}^{4} \mathrm{D}^{\circ}+20.3 \% 5 \mathrm{p}^{2}\left({ }^{3} \mathrm{P}\right) 4 \mathrm{f}^{4} \mathrm{G}^{\circ}$ \\
\hline 122137.90 & 122077 & 1.20 & 1.18 & 1.02 & $47.2 \% 5 \mathrm{p}^{2}\left({ }^{3} \mathrm{P}\right) 4 \mathrm{f}^{4} \mathrm{D}^{\circ}+36.3 \% 5 \mathrm{p}^{2}\left({ }^{3} \mathrm{P}\right) 4 \mathrm{f}^{4} \mathrm{G}^{\circ}$ \\
\hline 122616.65 & 122715 & 0.98 & 0.98 & 1.00 & $52.1 \% 5 \mathrm{p}^{2}\left({ }^{3} \mathrm{P}\right) 4 \mathrm{f}^{2} \mathrm{G}^{\circ}+24.7 \% 5 \mathrm{p}^{2}\left({ }^{3} \mathrm{P}\right) 4 \mathrm{f}^{4} \mathrm{G}^{\circ}$ \\
\hline 125983.78 & 125887 & 1.15 & 1.20 & 0.96 & $48.6 \% 5 p^{2}\left({ }^{3} \mathrm{P}\right) 4 \mathrm{f}^{4} \mathrm{~F}^{\circ}+16.5 \% 5 \mathrm{p}^{2}\left({ }^{1} \mathrm{D}\right) 4 \mathrm{f}^{2} \mathrm{G}^{\circ}$ \\
\hline $\begin{array}{r}126164.22 \\
J=9 / 2\end{array}$ & 126166 & 1.10 & 1.12 & 0.98 & $49.3 \% 5 \mathrm{p}^{2}\left({ }^{3} \mathrm{P}\right) 4 \mathrm{f}^{2} \mathrm{~F}^{\circ}+17.5 \% 5 \mathrm{p}^{2}\left({ }^{1} \mathrm{D}\right) 4 \mathrm{f}^{2} \mathrm{G}^{\circ}$ \\
\hline 122427.00 & 122487 & 1.21 & 1.25 & 0.97 & $57.6 \% 5 \mathrm{p}^{2}\left({ }^{3} \mathrm{P}\right) 4 \mathrm{f}^{4} \mathrm{G}^{\circ}+25.2 \% 5 \mathrm{p}^{2}\left({ }^{3} \mathrm{P}\right) 4 \mathrm{f}^{4} \mathrm{~F}^{\circ}$ \\
\hline $\begin{array}{r}125644.34 \\
J=11 / 2\end{array}$ & 125622 & 1.18 & 1.19 & 0.99 & $30.6 \% 5 \mathrm{p}^{2}\left({ }^{3} \mathrm{P}\right) 4 \mathrm{f}^{4} \mathrm{~F}^{\circ}+25.9 \% 5 \mathrm{p}^{2}\left({ }^{3} \mathrm{P}\right) 4 \mathrm{f}^{4} \mathrm{G}^{\circ}$ \\
\hline 125495.39 & 125563 & 1.24 & 1.31 & 0.94 & $77.5 \% 5 \mathrm{p}^{2}\left({ }^{3} \mathrm{P}\right) 4 \mathrm{f}^{4} \mathrm{G}^{\circ}+19.5 \% 5 \mathrm{p}^{2}\left({ }^{1} \mathrm{D}\right) 4 \mathrm{f}^{2} \mathrm{H}^{\circ}$ \\
\hline
\end{tabular}

Notes. ${ }^{(a)}$ Kramida et al. (2012). ${ }^{(b)}$ HFR + CPOL (this work).

but the experimental Landé $g$ factors follow the NIST database designations which agree with our HFR+CPOL calculation). In addition, it appears that it is actually the ab initio HFR order using both the CI considered in Tauheed \& Naz (2011) and our more extended CI expansion.

\section{Discussion}

The comparisons between the MCDHF and HFR+CPOL $\log g f$ in Te II and Te III are given in Figs. 1 and 2 respectively; only transitions with a gauge agreement better than $10 \%$ and $C F>$ 0.05 (in both MCDHF and HFR+CPOL) have been retained. In Te II, the average oscillator strength ratio between HFR+CPOL and MCDHF is $0.99 \pm 0.31$ (where the second number is the standard deviation) for $\log g f(\mathrm{HFR}+\mathrm{CPOL}) \geq-1$ suggesting an accuracy of about $60 \%$ (two times the standard deviation) for the strong lines reported in Table 8. Concerning Te III, this ratio becomes $1.21 \pm 0.80$ due to essentially a few ( 9 on a total of 65 lines) transitions that present strong disagreements between MCDHF and HFR+CPOL (factor two and more) 
W. Zhang et al.: Transition probabilities in Te II and Te III spectra

Table 5. Comparison between experimental and HFR+CPOL level energies and Landé factors in Te II (even levels).

\begin{tabular}{|c|c|c|c|c|c|}
\hline$E_{\operatorname{Exp}}^{a}\left(\mathrm{~cm}^{-1}\right)$ & $E_{\mathrm{Calc}^{b}}^{b}\left(\mathrm{~cm}^{-1}\right)$ & $g_{\text {Calc }}^{b}$ & $g_{\text {Exp }}{ }^{a}$ & $g_{\text {Calc }} / g_{\text {Exp }}$ & LS-composition $^{b}$ \\
\hline \multicolumn{6}{|l|}{$J=1 / 2$} \\
\hline 76300.87 & 76414 & 2.63 & 2.63 & 1.00 & $66.7 \% 5 \mathrm{~s} 5 \mathrm{p}^{4}\left({ }^{3} \mathrm{P}\right){ }^{4} \mathrm{P}+17.7 \% 5 \mathrm{p}^{2}\left({ }^{3} \mathrm{P}\right) 5 \mathrm{~d}^{4} \mathrm{P}$ \\
\hline 78448.22 & 78364 & 2.28 & 2.29 & 1.00 & $65.1 \% 5 \mathrm{p}^{2}\left({ }^{3} \mathrm{P}\right) 6 \mathrm{~s}{ }^{4} \mathrm{P}+15.7 \% 5 \mathrm{p}^{2}\left({ }^{3} \mathrm{P}\right) 6 \mathrm{~s}{ }^{2} \mathrm{P}$ \\
\hline 83577.41 & 83286 & 1.07 & 1.06 & 1.01 & $63.4 \% 5 \mathrm{p}^{2}\left({ }^{3} \mathrm{P}\right) 6 \mathrm{~s}^{2} \mathrm{P}+18.8 \% 5 \mathrm{p}^{2}\left({ }^{3} \mathrm{P}\right) 6 \mathrm{~s}^{4} \mathrm{P}$ \\
\hline 88796.16 & 88585 & 0.39 & 0.35 & 1.11 & $44.2 \% 5 \mathrm{p}^{2}\left({ }^{3} \mathrm{P}\right) 5 \mathrm{~d}^{4} \mathrm{D}+32.8 \% 5 \mathrm{p}^{2}\left({ }^{3} \mathrm{P}\right) 5 \mathrm{~d}^{2} \mathrm{P}$ \\
\hline 92691.51 & 92425 & 0.37 & 0.42 & 0.88 & $50.7 \% 5 \mathrm{p}^{2}\left({ }^{3} \mathrm{P}\right) 5 \mathrm{~d}^{4} \mathrm{D}+32.2 \% 5 \mathrm{p}^{2}\left({ }^{3} \mathrm{P}\right) 5 \mathrm{~d}^{2} \mathrm{P}$ \\
\hline 101065.37 & 100578 & 2.16 & 2.12 & 1.02 & $43.4 \% 5 \mathrm{p}^{2}\left({ }^{1} \mathrm{D}\right) 5 \mathrm{~d}^{2} \mathrm{~S}+19.3 \% 5 \mathrm{p}^{2}\left({ }^{3} \mathrm{P}\right) 5 \mathrm{~d}^{4} \mathrm{P}$ \\
\hline 102127.22 & 102377 & 2.30 & 2.26 & 1.02 & $49.9 \% 5 \mathrm{p}^{2}\left({ }^{3} \mathrm{P}\right) 5 \mathrm{~d}^{4} \mathrm{P}+13.2 \% 5 \mathrm{p}^{2}\left({ }^{1} \mathrm{D}\right) 5 \mathrm{~d}^{2} \mathrm{~S}$ \\
\hline 107521.8 & 108077 & 1.31 & & & $48.8 \% 5 \mathrm{p}^{2}\left({ }^{1} \mathrm{D}\right) 5 \mathrm{~d}^{2} \mathrm{P}+34.5 \% 5 \mathrm{p}^{2}\left({ }^{1} \mathrm{~S}\right) 6 \mathrm{~s}^{2} \mathrm{~S}$ \\
\hline 109005.8 & 109284 & 1.50 & & & $42.4 \% 5 \mathrm{p}^{2}\left({ }^{1} \mathrm{~S}\right) 6 \mathrm{~s}^{2} \mathrm{~S}+29.9 \% 5 \mathrm{p}^{2}\left({ }^{1} \mathrm{D}\right) 5 \mathrm{~d}^{2} \mathrm{P}$ \\
\hline 112823.93 & 112877 & 2.23 & 2.16 & 1.03 & $73.0 \% 5 \mathrm{p}^{2}\left({ }^{3} \mathrm{P}\right) 7 \mathrm{~s}{ }^{4} \mathrm{P}+16.3 \% 5 \mathrm{p}^{2}\left({ }^{3} \mathrm{P}\right) 7 \mathrm{~s}^{2} \mathrm{P}$ \\
\hline 117192.38 & 116980 & 0.99 & & & $31.0 \% 5 \mathrm{~s} 5 \mathrm{p}^{4}\left({ }^{3} \mathrm{P}\right){ }^{2} \mathrm{P}+26.6 \% 5 \mathrm{p}^{2}\left({ }^{3} \mathrm{P}\right) 6 \mathrm{~d}^{2} \mathrm{P}$ \\
\hline 118009.02 & 118319 & 1.10 & 1.16 & 0.95 & $71.0 \% 5 \mathrm{p}^{2}\left({ }^{3} \mathrm{P}\right) 7 \mathrm{~s}^{2} \mathrm{P}+19.9 \% 5 \mathrm{p}^{2}\left({ }^{3} \mathrm{P}\right) 7 \mathrm{~s}{ }^{4} \mathrm{P}$ \\
\hline 121106.21 & 121239 & 0.48 & 0.52 & 0.92 & $72.9 \% 5 \mathrm{p}^{2}\left({ }^{3} \mathrm{P}\right) 6 \mathrm{~d}{ }^{4} \mathrm{D}+5.9 \% 5 \mathrm{~s} 5 \mathrm{p}^{4}\left({ }^{1} \mathrm{~S}\right){ }^{2} \mathrm{~S}$ \\
\hline 123657.46 & 123709 & 1.35 & 1.15 & 1.17 & $27.9 \% 5 \mathrm{~s} 5 \mathrm{p}^{4}\left({ }^{1} \mathrm{~S}\right){ }^{2} \mathrm{~S}+15.2 \% 5 \mathrm{p}^{2}\left({ }^{3} \mathrm{P}\right) 6 \mathrm{~d}^{2} \mathrm{P}$ \\
\hline 125477.6 & 125286 & 2.38 & & & $73.0 \% 5 \mathrm{p}^{2}\left({ }^{3} \mathrm{P}\right) 6 \mathrm{~d}^{4} \mathrm{P}+5.6 \% 5 \mathrm{~s} 5 \mathrm{p}^{4}\left({ }^{1} \mathrm{~S}\right){ }^{2} \mathrm{~S}$ \\
\hline 126212.00 & 126144 & 2.06 & 2.03 & 1.01 & $64.1 \% 5 \mathrm{p}^{2}\left({ }^{3} \mathrm{P}\right) 8 \mathrm{~s}{ }^{4} \mathrm{P}+26.55 \mathrm{p}^{2}\left({ }^{3} \mathrm{P}\right) 8 \mathrm{~s}^{2} \mathrm{P}$ \\
\hline 128082.5 & 128374 & 0.85 & & & $30.2 \% 5 \mathrm{p}^{2}\left({ }^{3} \mathrm{P}\right) 6 \mathrm{~d}^{2} \mathrm{P}+20.4 \% 5 \mathrm{p}^{2}\left({ }^{3} \mathrm{P}\right) 7 \mathrm{~d}^{2} \mathrm{P}$ \\
\hline 134123.7 & 134153 & 0.74 & & & $64.0 \% 5 \mathrm{p}^{2}\left({ }^{1} \mathrm{D}\right) 6 \mathrm{~d}^{2} \mathrm{P}+11.4 \% 5 \mathrm{p}^{2}\left({ }^{3} \mathrm{P}\right) 7 \mathrm{~d}^{2} \mathrm{P}$ \\
\hline 136889.5 & 136501 & 1.20 & & & $38.5 \% 5 \mathrm{p}^{2}\left({ }^{3} \mathrm{P}\right) 7 \mathrm{~d}^{2} \mathrm{P}+31.5 \% 5 \mathrm{p}^{2}\left({ }^{1} \mathrm{D}\right) 6 \mathrm{~d}^{2} \mathrm{~S}$ \\
\hline $\begin{array}{r}141894.6 \\
J=3 / 2\end{array}$ & 141420 & 2.00 & & & $88.1 \% 5 \mathrm{p}^{2}\left({ }^{1} \mathrm{~S}\right) 7 \mathrm{~s}^{2} \mathrm{~S}+4.5 \% 5 \mathrm{p}^{2}\left({ }^{3} \mathrm{P}\right) 7 \mathrm{~s}{ }^{4} \mathrm{P}$ \\
\hline 74893.40 & 74913 & 1.71 & 1.71 & 1.00 & $74.0 \% 5 \mathrm{~s} 5 \mathrm{p}^{4}\left({ }^{3} \mathrm{P}\right){ }^{4} \mathrm{P}+18.8 \% 5 \mathrm{p}^{2}\left({ }^{3} \mathrm{P}\right) 5 \mathrm{~d}{ }^{4} \mathrm{P}$ \\
\hline 81895.43 & 81721 & 1.22 & 1.12 & 1.09 & $28.3 \% 5 \mathrm{p}^{2}\left({ }^{3} \mathrm{P}\right) 5 \mathrm{~d}^{2} \mathrm{P}+22.8 \% 5 \mathrm{p}^{2}\left({ }^{3} \mathrm{P}\right) 6 \mathrm{~s}^{4} \mathrm{P}$ \\
\hline 82743.33 & 82709 & 1.46 & 1.45 & 1.01 & $65.9 \% 5 \mathrm{p}^{2}\left({ }^{3} \mathrm{P}\right) 6 \mathrm{~s}{ }^{4} \mathrm{P}+12.5 \% 5 \mathrm{p}^{2}\left({ }^{3} \mathrm{P}\right) 5 \mathrm{~d}^{4} \mathrm{~F}$ \\
\hline 85159.66 & 85102 & 0.81 & 0.88 & 0.92 & $54.6 \% 5 \mathrm{p}^{2}\left({ }^{3} \mathrm{P}\right) 5 \mathrm{~d}^{4} \mathrm{~F}+22.3 \% 5 \mathrm{p}^{2}\left({ }^{3} \mathrm{P}\right) 5 \mathrm{~d}^{2} \mathrm{P}$ \\
\hline 86759.90 & 86713 & 0.92 & 0.94 & 0.98 & $27.2 \% 5 s 5 p^{4}\left({ }^{1} D\right)^{2} D+24.3 \% 5 p^{2}\left({ }^{1} D\right) 5 d^{2} D$ \\
\hline 88961.09 & 88944 & 1.17 & 1.17 & 1.00 & $31.2 \% 5 \mathrm{p}^{2}\left({ }^{3} \mathrm{P}\right) 6 \mathrm{~s}{ }^{2} \mathrm{P}+22.8 \% 5 \mathrm{p}^{2}\left({ }^{3} \mathrm{P}\right) 5 \mathrm{~d}^{4} \mathrm{D}$ \\
\hline 92191.47 & 92177 & 1.13 & 1.13 & 1.00 & $57.9 \% 5 \mathrm{p}^{2}\left({ }^{3} \mathrm{P}\right) 5 \mathrm{~d}^{4} \mathrm{D}+9.6 \% 5 \mathrm{~s} 5 \mathrm{p}^{4}\left({ }^{1} \mathrm{D}\right){ }^{2} \mathrm{D}$ \\
\hline 95208.37 & 95263 & 0.95 & 0.98 & 0.97 & $61.3 \% 5 \mathrm{p}^{2}\left({ }^{1} \mathrm{D}\right) 6 \mathrm{~s}^{2} \mathrm{D}+21.6 \% 5 \mathrm{p}^{2}\left({ }^{3} \mathrm{P}\right) 6 \mathrm{~s}^{2} \mathrm{P}$ \\
\hline 100740.75 & 100685 & 1.60 & 1.56 & 1.03 & $60.9 \% 5 \mathrm{p}^{2}\left({ }^{3} \mathrm{P}\right) 5 \mathrm{~d}{ }^{4} \mathrm{P}+13.0 \% 5 \mathrm{~s} 5 \mathrm{p}^{4}\left({ }^{3} \mathrm{P}\right){ }^{4} \mathrm{P}$ \\
\hline 102244.60 & 102377 & 0.90 & 0.95 & 0.96 & $60.1 \% 5 \mathrm{p}^{2}\left({ }^{3} \mathrm{P}\right) 5 \mathrm{~d}^{2} \mathrm{D}+8.8 \% 5 \mathrm{p}^{2}\left({ }^{1} \mathrm{~S}\right) 5 \mathrm{~d}^{2} \mathrm{D}$ \\
\hline 110136.3 & 110045 & 1.29 & & & $56.8 \% 5 \mathrm{p}^{2}\left({ }^{1} \mathrm{D}\right) 5 \mathrm{~d}^{2} \mathrm{P}+20.5 \% 5 \mathrm{~s} 5 \mathrm{p}^{4}\left({ }^{3} \mathrm{P}\right){ }^{2} \mathrm{P}$ \\
\hline 111856.1 & 112026 & 0.97 & & & $38.9 \% 5 \mathrm{p}^{2}\left({ }^{1} \mathrm{D}\right) 5 \mathrm{~d}^{2} \mathrm{D}+20.4 \% 5 \mathrm{~s} 5 \mathrm{p}^{4}\left({ }^{1} \mathrm{D}\right)^{2} \mathrm{D}$ \\
\hline 115700.56 & 115643 & 0.95 & 0.91 & 1.04 & $23.4 \% 5 \mathrm{p}^{2}\left({ }^{3} \mathrm{P}\right) 6 \mathrm{~d}^{4} \mathrm{~F}+23.9 \% 5 \mathrm{p}^{2}\left({ }^{3} \mathrm{P}\right) 6 \mathrm{~d}^{2} \mathrm{P}$ \\
\hline 117264.02 & 117417 & 1.23 & 0.98 & 1.26 & $39.1 \% 5 \mathrm{p}^{2}\left({ }^{3} \mathrm{P}\right) 7 \mathrm{~s}{ }^{4} \mathrm{P}+18.1 \% 5 \mathrm{p}^{2}\left({ }^{3} \mathrm{P}\right) 6 \mathrm{~d}^{4} \mathrm{~F}$ \\
\hline 117339.70 & 117273 & 1.34 & 1.60 & 1.54 & $51.1 \% 5 \mathrm{p}^{2}\left({ }^{3} \mathrm{P}\right) 7 \mathrm{~s}{ }^{4} \mathrm{P}+13.6 \% 5 \mathrm{p}^{2}\left({ }^{3} \mathrm{P}\right) 6 \mathrm{~d}^{4} \mathrm{~F}$ \\
\hline 118325.5 & 118325 & 0.78 & & & $48.6 \% 5 p^{2}\left({ }^{1} S\right) 5 d^{2} D+16.0 \% 5 p^{2}\left({ }^{3} P\right) 6 d^{4} F$ \\
\hline 121173.94 & 121673 & 1.21 & 1.23 & 0.98 & $33.8 \% 5 \mathrm{p}^{2}\left({ }^{3} \mathrm{P}\right) 7 \mathrm{~s}{ }^{2} \mathrm{P}+27.2 \% 5 \mathrm{p}^{2}\left({ }^{3} \mathrm{P}\right) 6 \mathrm{~d}^{4} \mathrm{D}$ \\
\hline 121518.93 & 121285 & 1.21 & 1.20 & 1.01 & $30.0 \% 5 \mathrm{p}^{2}\left({ }^{3} \mathrm{P}\right) 7 \mathrm{~s}{ }^{2} \mathrm{P}+23.2 \% 5 \mathrm{p}^{2}\left({ }^{3} \mathrm{P}\right) 6 \mathrm{~d}^{4} \mathrm{D}$ \\
\hline 124082.07 & 124389 & 1.09 & 1.10 & 0.99 & $18.7 \% 5 \mathrm{p}^{2}\left({ }^{3} \mathrm{P}\right) 6 \mathrm{~d}^{2} \mathrm{P}+16.3 \% 5 \mathrm{p}^{2}\left({ }^{3} \mathrm{P}\right) 6 \mathrm{~d}^{2} \mathrm{D}$ \\
\hline 125066.06 & 124865 & 1.50 & 1.52 & 0.99 & $55.1 \% 5 \mathrm{p}^{2}\left({ }^{3} \mathrm{P}\right) 6 \mathrm{~d}^{4} \mathrm{P}+21.6 \% 5 \mathrm{p}^{2}\left({ }^{3} \mathrm{P}\right) 6 \mathrm{~d}^{4} \mathrm{D}$ \\
\hline 126516.86 & 126645 & 0.99 & 0.98 & 1.01 & $25.9 \% 5 \mathrm{p}^{2}\left({ }^{3} \mathrm{P}\right) 6 \mathrm{~d}^{2} \mathrm{D}+19.9 \% 5 \mathrm{p}^{2}\left({ }^{3} \mathrm{P}\right) 6 \mathrm{~d}^{2} \mathrm{P}$ \\
\hline 129789.2 & 129999 & 1.08 & & & $58.4 \% 5 \mathrm{p}^{2}\left({ }^{1} \mathrm{D}\right) 7 \mathrm{~s}^{2} \mathrm{D}+16.7 \% 5 \mathrm{p}^{2}\left({ }^{3} \mathrm{P}\right) 7 \mathrm{~s}^{2} \mathrm{P}$ \\
\hline 134495.3 & 134814 & 1.07 & & & $37.9 \% 5 \mathrm{p}^{2}\left({ }^{1} \mathrm{D}\right) 6 \mathrm{~d}^{2} \mathrm{D}+11.7 \% 5 \mathrm{p}^{2}\left({ }^{3} \mathrm{P}\right) 7 \mathrm{~d}^{4} \mathrm{P}$ \\
\hline 135582.2 & 135600 & 0.93 & & & $34.0 \% 5 \mathrm{p}^{2}\left({ }^{3} \mathrm{P}\right) 7 \mathrm{~d}^{2} \mathrm{D}+28.4 \% 5 \mathrm{p}^{2}\left({ }^{1} \mathrm{D}\right) 6 \mathrm{~d}^{2} \mathrm{D}$ \\
\hline 147105.3 & 147607 & 0.80 & & & $88.8 \% 5 \mathrm{p}^{2}\left({ }^{1} \mathrm{~S}\right) 6 \mathrm{~d}^{2} \mathrm{D}+2.8 \% 5 \mathrm{p}^{2}\left({ }^{3} \mathrm{P}\right) 6 \mathrm{~d}^{2} \mathrm{D}$ \\
\hline$J=5 / 2$ & & & & & \\
\hline 71192.526 & 71157 & 1.59 & 1.59 & 1.00 & $76.3 \% 5 \mathrm{~s} 5 \mathrm{p}^{4}\left({ }^{3} \mathrm{P}\right){ }^{4} \mathrm{P}+16.8 \% 5 \mathrm{p}^{2}\left({ }^{3} \mathrm{P}\right) 5 \mathrm{~d}{ }^{4} \mathrm{P}$ \\
\hline 85049.41 & 85283 & 1.10 & 1.09 & 1.01 & $63.6 \% 5 p^{2}\left({ }^{3} \mathrm{P}\right) 5 \mathrm{~d}^{4} \mathrm{~F}+11.0 \% 5 \mathrm{p}^{2}\left({ }^{3} \mathrm{P}\right) 5 \mathrm{~d}^{4} \mathrm{D}$ \\
\hline 85591.83 & 85477 & 1.50 & 1.50 & 1.00 & $72.3 \% 5 \mathrm{p}^{2}\left({ }^{3} \mathrm{P}\right) 6 \mathrm{~s}{ }^{4} \mathrm{P}+17.6 \% 5 \mathrm{p}^{2}\left({ }^{1} \mathrm{D}\right) 6 \mathrm{~s}^{2} \mathrm{D}$ \\
\hline 87404.54 & 87546 & 1.26 & 1.25 & 1.00 & $36.6 \% 5 \mathrm{~s} 5 \mathrm{p}^{4}\left({ }^{1} \mathrm{D}\right){ }^{2} \mathrm{D}+32.6 \% 5 \mathrm{p}^{2}\left({ }^{1} \mathrm{D}\right) 5 \mathrm{~d}^{2} \mathrm{D}$ \\
\hline 88924.81 & 88852 & 0.94 & 0.94 & 1.00 & $36.5 \% 5 \mathrm{p}^{2}\left({ }^{3} \mathrm{P}\right) 5 \mathrm{~d}^{2} \mathrm{~F}+35.6 \% 5 \mathrm{p}^{2}\left({ }^{1} \mathrm{D}\right) 5 \mathrm{~d}^{2} \mathrm{~F}$ \\
\hline 92793.22 & 92782 & 1.25 & 1.24 & 1.01 & $50.6 \% 5 \mathrm{p}^{2}\left({ }^{3} \mathrm{P}\right) 5 \mathrm{~d}^{4} \mathrm{D}+12.2 \% 5 \mathrm{p}^{2}\left({ }^{3} \mathrm{P}\right) 5 \mathrm{~d}^{2} \mathrm{~F}$ \\
\hline 94860.63 & 95016 & 1.26 & 1.27 & 0.99 & $74.1 \% 5 \mathrm{p}^{2}\left({ }^{1} \mathrm{D}\right) 6 \mathrm{~s}^{2} \mathrm{D}+15.9 \% 5 \mathrm{p}^{2}\left({ }^{3} \mathrm{P}\right) 6 \mathrm{~s}^{4} \mathrm{P}$ \\
\hline 99229.68 & 99054 & 1.53 & 1.51 & 1.01 & $64.7 \% 5 \mathrm{p}^{2}\left({ }^{3} \mathrm{P}\right) 5 \mathrm{~d}{ }^{4} \mathrm{P}+10.1 \% 5 \mathrm{~s} 5 \mathrm{p}^{4}\left({ }^{3} \mathrm{P}\right){ }^{4} \mathrm{P}$ \\
\hline 102703.5 & 102788 & 1.07 & 1.12 & 0.96 & $43.1 \% 5 \mathrm{p}^{2}\left({ }^{3} \mathrm{P}\right) 5 \mathrm{~d}^{2} \mathrm{D}+21.0 \% 5 \mathrm{p}^{2}\left({ }^{1} \mathrm{D}\right) 5 \mathrm{~d}^{2} \mathrm{~F}$ \\
\hline 108819.4 & 108578 & 1.03 & & & $33.6 \% 5 \mathrm{p}^{2}\left({ }^{3} \mathrm{P}\right) 5 \mathrm{~d}^{2} \mathrm{D}+26.1 \% 5 \mathrm{p}^{2}\left({ }^{1} \mathrm{D}\right) 5 \mathrm{~d}^{2} \mathrm{~F}$ \\
\hline 113564.5 & 113272 & 1.21 & & & $50.3 \% 5 \mathrm{p}^{2}\left({ }^{1} \mathrm{D}\right) 5 \mathrm{~d}^{2} \mathrm{D}+20.7 \% 5 \mathrm{~s} 5 \mathrm{p}^{4}\left({ }^{1} \mathrm{D}\right){ }^{2} \mathrm{D}$ \\
\hline 116837.31 & 116886 & 1.21 & 1.20 & 1.01 & $30.9 \% 5 \mathrm{p}^{2}\left({ }^{3} \mathrm{P}\right) 6 \mathrm{~d}^{4} \mathrm{~F}+15.0 \% 5 \mathrm{p}^{2}\left({ }^{3} \mathrm{P}\right) 6 \mathrm{~d}^{4} \mathrm{P}$ \\
\hline 118420.6 & 118358 & 1.19 & & & $64.0 \% 5 \mathrm{p}^{2}\left({ }^{1} \mathrm{~S}\right) 5 \mathrm{~d}^{2} \mathrm{D}+8.2 \% 5 \mathrm{~s} 5 \mathrm{p}^{4}\left({ }^{1} \mathrm{D}\right){ }^{2} \mathrm{D}$ \\
\hline 120617.13 & 120516 & 1.51 & 1.51 & 1.00 & $75.5 \% 5 \mathrm{p}^{2}\left({ }^{3} \mathrm{P}\right) 7 \mathrm{~s}{ }^{4} \mathrm{P}+18.5 \% 5 \mathrm{p}^{2}\left({ }^{1} \mathrm{D}\right) 7 \mathrm{~s}^{2} \mathrm{D}$ \\
\hline 121063.80 & 121030 & 1.20 & 1.2 & 1.00 & $49.8 \% 5 \mathrm{p}^{2}\left({ }^{3} \mathrm{P}\right) 6 \mathrm{~d}{ }^{4} \mathrm{~F}+24.4 \% 5 \mathrm{p}^{2}\left({ }^{3} \mathrm{P}\right) 6 \mathrm{~d}^{4} \mathrm{P}$ \\
\hline 122196.84 & 122057 & 1.06 & 1.07 & 0.99 & $59.4 \% 5 \mathrm{p}^{2}\left({ }^{3} \mathrm{P}\right) 6 \mathrm{~d}^{2} \mathrm{~F}+19.1 \% 5 \mathrm{p}^{2}\left({ }^{3} \mathrm{P}\right) 6 \mathrm{~d}^{4} \mathrm{P}$ \\
\hline
\end{tabular}

Notes. ${ }^{(a)}$ Kramida et al. (2012). ${ }^{(b)}$ HFR + CPOL (this work). 
Table 5. continued.

\begin{tabular}{|c|c|c|c|c|c|}
\hline$E_{\operatorname{Exp}}{ }^{a}\left(\mathrm{~cm}^{-1}\right)$ & $E_{\mathrm{Calc}}^{b}\left(\mathrm{~cm}^{-1}\right)$ & $g_{\text {Calc }}^{b}$ & $g_{\operatorname{Exp}}{ }^{a}$ & $g_{\text {Calc }} / g_{\text {Exp }}$ & LS-composition $^{b}$ \\
\hline \multicolumn{6}{|l|}{$J=5 / 2$} \\
\hline 124646.39 & 124563 & 1.33 & 1.32 & 1.01 & $45.9 \% 5 \mathrm{p}^{2}\left({ }^{3} \mathrm{P}\right) 6 \mathrm{~d}{ }^{4} \mathrm{D}+20.9 \% 5 \mathrm{p}^{2}\left({ }^{3} \mathrm{P}\right) 6 \mathrm{~d}{ }^{4} \mathrm{P}$ \\
\hline 125906.03 & 125815 & 1.15 & 1.17 & 0.98 & $41.5 \% 5 \mathrm{p}^{2}\left({ }^{3} \mathrm{P}\right) 6 \mathrm{~d}^{2} \mathrm{D}+17.5 \% 5 \mathrm{p}^{2}\left({ }^{1} \mathrm{D}\right) 6 \mathrm{~d}^{2} \mathrm{~F}$ \\
\hline 128348.0 & 128045 & 1.21 & & & $33.7 \% 5 \mathrm{p}^{2}\left({ }^{3} \mathrm{P}\right) 7 \mathrm{~d}^{4} \mathrm{~F}+27.6 \% 5 \mathrm{p}^{2}\left({ }^{3} \mathrm{P}\right) 7 \mathrm{~d}^{4} \mathrm{D}$ \\
\hline 129897.22 & 129742 & 1.28 & 1.29 & 0.99 & $76.6 \% 5 \mathrm{p}^{2}\left({ }^{1} \mathrm{D}\right) 7 \mathrm{~s}^{2} \mathrm{D}+20.0 \% 5 \mathrm{p}^{2}\left({ }^{3} \mathrm{P}\right) 7 \mathrm{~d}^{4} \mathrm{P}$ \\
\hline 133904.7 & 134296 & 1.07 & & & $38.2 \% 5 \mathrm{p}^{2}\left({ }^{3} \mathrm{P}\right) 7 \mathrm{~d}^{2} \mathrm{D}+34.1 \% 5 \mathrm{p}^{2}\left({ }^{1} \mathrm{D}\right) 6 \mathrm{~d}^{2} \mathrm{~F}$ \\
\hline 135093.1 & 135152 & 1.20 & & & $46.1 \% 5 \mathrm{p}^{2}\left({ }^{1} \mathrm{D}\right) 6 \mathrm{~d}^{2} \mathrm{D}+11.6 \% 5 \mathrm{p}^{2}\left({ }^{3} \mathrm{P}\right) 7 \mathrm{~d}^{4} \mathrm{D}$ \\
\hline 136881.7 & 137065 & 1.10 & & & $27.1 \% 5 \mathrm{p}^{2}\left({ }^{3} \mathrm{P}\right) 7 \mathrm{~d}^{2} \mathrm{D}+15.6 \% 5 \mathrm{p}^{2}\left({ }^{3} \mathrm{P}\right) 6 \mathrm{~d}^{2} \mathrm{D}$ \\
\hline $\begin{array}{r}147870.1 \\
J=7 / 2\end{array}$ & \multicolumn{4}{|c|}{$J=7 / 2$} & $87.7 \% 5 \mathrm{p}^{2}\left({ }^{1} \mathrm{~S}\right) 6 \mathrm{~d}^{2} \mathrm{D}+2.2 \% 5 \mathrm{p}^{2}\left({ }^{3} \mathrm{P}\right) 6 \mathrm{~d}^{2} \mathrm{~F}$ \\
\hline 87899.86 & 88226 & 1.27 & 1.26 & 1.00 & $78.2 \% 5 \mathrm{p}^{2}\left({ }^{3} \mathrm{P}\right) 5 \mathrm{~d}^{4} \mathrm{~F}+16.7 \% 5 \mathrm{p}^{2}\left({ }^{3} \mathrm{P}\right) 5 \mathrm{~d}^{4} \mathrm{D}$ \\
\hline 90797.21 & 90677 & 1.25 & 1.25 & 1.00 & $35.0 \% 5 \mathrm{p}^{2}\left({ }^{3} \mathrm{P}\right) 5 \mathrm{~d}^{4} \mathrm{D}+30.9 \% 5 \mathrm{p}^{2}\left({ }^{1} \mathrm{D}\right) 5 \mathrm{~d}^{2} \mathrm{~F}$ \\
\hline 96534.6 & 96570 & 1.25 & 1.24 & 1.01 & $41.9 \% 5 \mathrm{p}^{2}\left({ }^{3} \mathrm{P}\right) 5 \mathrm{~d}^{4} \mathrm{D}+28.6 \% 5 \mathrm{p}^{2}\left({ }^{3} \mathrm{P}\right) 5 \mathrm{~d}^{2} \mathrm{~F}$ \\
\hline 100835.8 & 100736 & 0.97 & 0.98 & 0.99 & $71.5 \% 5 \mathrm{p}^{2}\left({ }^{1} \mathrm{D}\right) 5 \mathrm{~d}^{2} \mathrm{G}+22.7 \% 5 \mathrm{p}^{2}\left({ }^{1} \mathrm{D}\right) 5 \mathrm{~d}^{2} \mathrm{~F}$ \\
\hline 107244.4 & 107304 & 1.12 & 1.19 & 0.94 & $46.0 \% 5 \mathrm{p}^{2}\left({ }^{3} \mathrm{P}\right) 5 \mathrm{~d}^{2} \mathrm{~F}+29.8 \% 5 \mathrm{p}^{2}\left({ }^{1} \mathrm{D}\right) 5 \mathrm{~d}^{2} \mathrm{~F}$ \\
\hline 120667.5 & 120673 & 1.29 & & & $59.2 \% 5 \mathrm{p}^{2}\left({ }^{3} \mathrm{P}\right) 6 \mathrm{~d}^{4} \mathrm{~F}+30.5 \% 5 \mathrm{p}^{2}\left({ }^{3} \mathrm{P}\right) 6 \mathrm{~d}^{4} \mathrm{D}$ \\
\hline 123654.56 & 123770 & 1.27 & 1.26 & 1.01 & $37.2 \% 5 \mathrm{p}^{2}\left({ }^{3} \mathrm{P}\right) 6 \mathrm{~d}^{4} \mathrm{D}+29.0 \% 5 \mathrm{p}^{2}\left({ }^{3} \mathrm{P}\right) 6 \mathrm{~d}{ }^{4} \mathrm{~F}$ \\
\hline 125967.10 & 125807 & 1.15 & 1.15 & 1.00 & $57.4 \% 5 \mathrm{p}^{2}\left({ }^{3} \mathrm{P}\right) 6 \mathrm{~d}^{2} \mathrm{~F}+15.5 \% 5 \mathrm{p}^{2}\left({ }^{3} \mathrm{P}\right) 6 \mathrm{~d}^{4} \mathrm{D}$ \\
\hline 133042.0 & 132792 & 1.19 & & & $58.9 \% 5 \mathrm{p}^{2}\left({ }^{1} \mathrm{D}\right) 6 \mathrm{~d}^{2} \mathrm{~F}+11.2 \% 5 \mathrm{p}^{2}\left({ }^{3} \mathrm{P}\right) 6 \mathrm{~d}^{4} \mathrm{D}$ \\
\hline $\begin{array}{r}133769.00 \\
J=9 / 2\end{array}$ & 133682 & \multicolumn{4}{|c|}{$J=9 / 2$} \\
\hline 90519.67 & 90875 & 1.31 & 1.31 & 1.00 & $86.2 \% 5 \mathrm{p}^{2}\left({ }^{3} \mathrm{P}\right) 5 \mathrm{~d}^{4} \mathrm{~F}+11.2 \% 5 \mathrm{p}^{2}\left({ }^{1} \mathrm{D}\right) 5 \mathrm{~d}^{2} \mathrm{G}$ \\
\hline & 102262 & 1.14 & & & $87.0 \% 5 \mathrm{p}^{2}\left({ }^{1} \mathrm{D}\right) 5 \mathrm{~d}^{2} \mathrm{G}+11.0 \% 5 \mathrm{p}^{2}\left({ }^{3} \mathrm{P}\right) 5 \mathrm{~d}^{4} \mathrm{~F}$ \\
\hline 123649.92 & 123705 & 1.30 & 1.30 & 1.00 & $80.8 \% 5 \mathrm{p}^{2}\left({ }^{3} \mathrm{P}\right) 6 \mathrm{~d}^{4} \mathrm{~F}+16.0 \% 5 \mathrm{p}^{2}\left({ }^{1} \mathrm{D}\right) 5 \mathrm{~d}^{2} \mathrm{G}$ \\
\hline
\end{tabular}

Table 6. Comparison between experimental and HFR+CPOL level energies and Landé factors in Te III (even levels).

\begin{tabular}{rrrrll}
\hline \hline$E_{\text {Exp }}{ }^{a}\left(\mathrm{~cm}^{-1}\right)$ & $E_{\text {Calc }}{ }^{b}\left(\mathrm{~cm}^{-1}\right)$ & $g_{\operatorname{Exp}}{ }^{c}$ & $g_{\text {Calc }}{ }^{a}$ & $g_{\text {Calc }} / g_{\text {Exp }}$ & LS-composition \\
\hline$J=0$ & & & & & \\
0.0 & 0 & & & & $90.4 \% 5 \mathrm{p}^{2}{ }^{3} \mathrm{P}+6.5 \% 5 \mathrm{p}^{2}{ }^{1} \mathrm{~S}$ \\
30398.3 & 30398 & & & & $88.1 \% 5 \mathrm{p}^{2}{ }^{1} \mathrm{~S}+6.6 \% 5 \mathrm{p}^{2} \mathrm{P}$ \\
132262.4 & 132175 & & & & $86.9 \% 5 \mathrm{p} 6 \mathrm{p}^{3} \mathrm{P}+10.0 \% 5 \mathrm{p} 6 \mathrm{p}{ }^{1} \mathrm{~S}$ \\
$J=1$ & & & & & \\
4757.2 & 4767 & & 1.50 & & $96.9 \% 5 \mathrm{p}^{2}{ }^{3} \mathrm{P}+1.0 \% 5 \mathrm{~s} 5 \mathrm{p}^{2}\left({ }^{1} \mathrm{D}\right) 5 \mathrm{~d}{ }^{3} \mathrm{P}$ \\
128617.9 & 128783 & 0.68 & 0.72 & 1.05 & $60.4 \% 5 \mathrm{p}^{3} \mathrm{D}+33.9 \% 5 \mathrm{p} 6 \mathrm{p}{ }^{1} \mathrm{P}$ \\
132116.7 & 131959 & 1.24 & 1.30 & 1.05 & $44.9 \% 5 \mathrm{p} 6 \mathrm{p}^{3} \mathrm{P}+18.7 \% 5 \mathrm{p} 6 \mathrm{p}{ }^{1} \mathrm{P}$ \\
138289.7 & 138214 & 1.02 & 1.13 & 1.11 & $42.0 \% 5 \mathrm{p} 6 \mathrm{p}^{3} \mathrm{P}+36.8 \% 5 \mathrm{p} 6 \mathrm{p}{ }^{1} \mathrm{P}$ \\
141803.0 & 141692 & 1.76 & 1.86 & 1.06 & $79.6 \% 5 \mathrm{p} 6 \mathrm{p}^{3} \mathrm{~S}+9.7 \% 5 \mathrm{p} 6 \mathrm{p}^{3} \mathrm{P}$ \\
$J=2$ & & & & & \\
8167.0 & 8153 & & 1.39 & & $75.8 \% 5 \mathrm{p}^{2}{ }^{3} \mathrm{P}+20.9 \% 5 \mathrm{p}^{2}{ }^{1} \mathrm{D}$ \\
17359.8 & 17364 & & 1.11 & & $75.3 \% 5 \mathrm{p}^{2}{ }^{1} \mathrm{D}+20.9 \% 5 \mathrm{p}^{2}{ }^{3} \mathrm{P}$ \\
132329.1 & 132401 & 1.16 & 1.20 & 1.03 & $67.9 \% 5 \mathrm{p} 6 \mathrm{p}^{3} \mathrm{D}+15.1 \% 5 \mathrm{p} 6 \mathrm{p}^{3} \mathrm{P}$ \\
139664.5 & 139611 & 1.43 & 1.37 & 0.96 & $62.1 \% 5 \mathrm{p} 6 \mathrm{p}^{3} \mathrm{P}+25.7 \% 5 \mathrm{p} 6 \mathrm{p}{ }^{3} \mathrm{D}$ \\
142982.0 & 143212 & 1.14 & 1.11 & 0.97 & $74.2 \% 5 \mathrm{p} 6 \mathrm{p}{ }^{1} \mathrm{D}+19.5 \% 5 \mathrm{p} 6 \mathrm{p}{ }^{3} \mathrm{P}$ \\
$J=3$ & & & & & \\
139949.7 & 139970 & 1.28 & 1.33 & 1.04 & $96.2 \% 5 \mathrm{p} 6 \mathrm{p}^{3} \mathrm{D}+1.1 \% 5 \mathrm{p} 4 \mathrm{f}^{3} \mathrm{D}$ \\
\hline
\end{tabular}

Notes. ${ }^{(a)}$ The $5 p^{2}$ levels are taken from Tauheed \& Naz (2011) and the 5p6p levels are from Kramida et al. (2012). ${ }^{(b)}$ HFR + CPOL (this work). (c) Kramida et al. (2012).

values. Discarding these lines, we obtain a ratio of $1.07 \pm 0.31$. For these transitions, the MCDHF transition probabilities prove to have poorly converged; this is illustrated in Fig. 3 where the $A$-values in both gauges (circles and squares for Babushkin and Coulomb gauges) of one of the problematic transitions $\left(5 \mathrm{~s}^{2} 5 \mathrm{p}^{2}{ }^{3} \mathrm{P}_{1}-5 \mathrm{~s}^{2} 5 \mathrm{p} 6 \mathrm{~s}^{1} \mathrm{P}_{1}^{\mathrm{o}}\right)$ along with those of a converged transition $\left(5 \mathrm{~s}^{2} 5 \mathrm{p}^{2}{ }^{3} \mathrm{P}_{2}-5 \mathrm{~s}^{2} 5 \mathrm{p} 6 \mathrm{~s}{ }^{3} \mathrm{P}_{1}^{\mathrm{o}}\right.$; diamonds for Babushkin and triangles for Coulomb) are plotted as a function of the calculation step. More correlation orbitals in the active set are clearly needed to stabilize these particular $A$-values but these calculations were not undertaken in the present work.

\section{Conclusions}

A first set of transition probabilities has been obtained for 439 transitions of Te II in the spectral range between 77 and $997 \mathrm{~nm}$ and for 284 transitions of Te III in the range 52-901 nm. Their accuracy has been assessed through the 
W. Zhang et al.: Transition probabilities in Te II and Te III spectra

Table 7. Comparison between experimental and HFR+CPOL level energies and Landé factors in Te III (odd levels).

\begin{tabular}{|c|c|c|c|c|c|}
\hline$E_{\operatorname{Exp}}{ }^{a}\left(\mathrm{~cm}^{-1}\right)$ & $E_{\text {Calc }}^{b}\left(\mathrm{~cm}^{-1}\right)$ & $g_{\mathrm{Exp}}{ }^{b}$ & $g_{\text {Calc }}{ }^{c}$ & $g_{\text {Calc }} / g_{\text {Exp }}$ & LS-composition $^{b}$ \\
\hline \multicolumn{6}{|l|}{$J=0$} \\
\hline 96061.6 & 96252 & & & & $78.4 \% 5 \mathrm{~s} 5 \mathrm{p}^{3}\left({ }^{2} \mathrm{P}\right){ }^{3} \mathrm{P}^{\circ}+18.1 \% 5 \mathrm{p} 5 \mathrm{~d}^{3} \mathrm{P}^{\circ}$ \\
\hline 107470.0 & 107325 & & & & $95.5 \% 5 \mathrm{p} 6 \mathrm{~s}^{3} \mathrm{P}^{\circ}+1.5 \% 5 \mathrm{p}^{3}\left({ }^{2} \mathrm{P}\right) 6 \mathrm{~s}^{3} \mathrm{P}^{\circ}$ \\
\hline 122541.0 & 122457 & & & & $77.5 \% 5 \mathrm{p} 5 \mathrm{~d}^{3} \mathrm{P}^{\circ}+17.6 \% 5 \mathrm{~s} 5 \mathrm{p}^{3}\left({ }^{2} \mathrm{P}\right){ }^{3} \mathrm{P}^{\circ}$ \\
\hline 160940.7 & 160923 & & & & $99.7 \% 5 \mathrm{p} 7 \mathrm{~s}^{3} \mathrm{P}^{\circ}+0.1 \% 5 \mathrm{p} 6 \mathrm{~d}^{3} \mathrm{P}^{\circ}$ \\
\hline 172389.2 & 172347 & & & & $95.7 \% 5 \mathrm{p} 6 \mathrm{~d}^{3} \mathrm{P}^{\circ}+1.8 \% 5 \mathrm{p}^{3}\left({ }^{2} \mathrm{P}\right) 6 \mathrm{~d}^{3} \mathrm{P}^{\circ}$ \\
\hline 184537.3 & 184527 & & & & $99.9 \% 5 \mathrm{p} 8 \mathrm{~s}^{3} \mathrm{P}^{\circ}$ \\
\hline 194253.9 & 194360 & & & & $98.8 \% 5 \mathrm{p} 7 \mathrm{~d}^{3} \mathrm{P}^{\circ}+0.5 \% 5 \mathrm{~s} 5 \mathrm{p}^{2}\left({ }^{3} \mathrm{P}\right) 6 \mathrm{p}^{3} \mathrm{P}^{\circ}$ \\
\hline \multicolumn{6}{|r|}{${ }^{-1}$} \\
\hline 82889.1 & 82867 & & 0.59 & & $72.5 \% 5 \mathrm{~s} 5 \mathrm{p}^{3}\left({ }^{2} \mathrm{D}\right){ }^{3} \mathrm{D}^{\circ}+14.6 \% 5 \mathrm{p} 5 \mathrm{~d}^{3} \mathrm{D}^{\circ}$ \\
\hline 96581.5 & 96665 & & 1.43 & & $69.2 \% 5 \mathrm{~s} 5 \mathrm{p}^{3}\left({ }^{2} \mathrm{P}\right){ }^{3} \mathrm{P}^{\circ}+17.1 \% 5 \mathrm{p}^{2} \mathrm{~d}^{3} \mathrm{P}^{\circ}$ \\
\hline 107726.6 & 107876 & 1.37 & 1.38 & 1.00 & $71.1 \% 5 \mathrm{p} 6 \mathrm{~s}^{3} \mathrm{P}^{\circ}+22.9 \% 5 \mathrm{p}^{\circ} \mathrm{s}^{1} \mathrm{P}^{\circ}$ \\
\hline 114216.4 & 114186 & 1.00 & 1.63 & 1.63 & $57.3 \% 5 \mathrm{~s} 5 \mathrm{p}^{3}\left({ }^{4} \mathrm{~S}\right){ }^{3} \mathrm{~S}^{\circ}+20.8 \% 5 \mathrm{~s} 5 \mathrm{p}^{3}\left({ }^{2} \mathrm{P}\right){ }^{1} \mathrm{P}^{\circ}$ \\
\hline 115747.6 & 115561 & & 1.02 & & $26.4 \% 5 \mathrm{p} 6 \mathrm{~s}^{1} \mathrm{P}^{\circ}+21.7 \% 5 \mathrm{p} 5 \mathrm{~d}^{3} \mathrm{D}^{\circ}$ \\
\hline 117796.1 & 118010 & 1.26 & 0.95 & 0.75 & $35.1 \% 5 \mathrm{p} 5 \mathrm{~d}^{3} \mathrm{D}^{\circ}+29.9 \% 5 \mathrm{p} 6 \mathrm{~s}^{1} \mathrm{P}^{\circ}$ \\
\hline 122127.4 & 121874 & & 1.17 & & $31.9 \% 5 \mathrm{p} 5 \mathrm{~d}^{3} \mathrm{P}^{\circ}+15.9 \% 5 \mathrm{p} 5 \mathrm{~d}^{3} \mathrm{D}^{\circ}$ \\
\hline 124787.9 & 124725 & & 1.33 & & $26.5 \% 5 \mathrm{p} 5 \mathrm{~d}^{3} \mathrm{P}^{\circ}+23.1 \% 5 \mathrm{p} 5 \mathrm{~d}^{1} \mathrm{P}^{\circ}$ \\
\hline 136476.2 & 136268 & & 1.02 & & $42.9 \% 5 \mathrm{~s} 5 \mathrm{p}^{3}\left({ }^{2} \mathrm{P}\right){ }^{1} \mathrm{P}^{\circ}+39.6 \% 5 \mathrm{p} 5 \mathrm{~d}^{1} \mathrm{P}^{\circ}$ \\
\hline 161196.5 & 161214 & 1.43 & 1.35 & 0.94 & $70.1 \% 5 \mathrm{p} 7 \mathrm{~s}^{3} \mathrm{P}^{\circ}+29.0 \% 5 \mathrm{p} 7 \mathrm{~s}^{1} \mathrm{P}^{\circ}$ \\
\hline 163334.2 & 163237 & & 0.76 & & $62.4 \% 5 \mathrm{p} 6 \mathrm{~d}^{3} \mathrm{D}^{\circ}+16.8 \% 5 \mathrm{p} 6 \mathrm{~d}^{1} \mathrm{P}^{\circ}$ \\
\hline 170586.9 & 170577 & & 1.12 & & $64.6 \% 5 \mathrm{p} 7 \mathrm{~s}^{1} \mathrm{P}^{\circ}+26.9 \% 5 \mathrm{p} 7 \mathrm{~s}^{3} \mathrm{P}^{\circ}$ \\
\hline 172159.0 & 172100 & & 1.28 & & $71.4 \% 5 \mathrm{p} 6 \mathrm{~d}^{3} \mathrm{P}^{\circ}+19.5 \% 5 \mathrm{p} 6 \mathrm{~d}^{3} \mathrm{D}^{\circ}$ \\
\hline 174499.3 & 174603 & & 1.00 & & $72.1 \% 5 \mathrm{p} 6 \mathrm{~d}^{1} \mathrm{P}^{\circ}+9.0 \% 5 \mathrm{p} 6 \mathrm{~d}^{3} \mathrm{D}^{\circ}$ \\
\hline 184657.0 & 184667 & & 1.34 & & $67.7 \% 5 \mathrm{p} 8 \mathrm{~s}^{3} \mathrm{P}^{\circ}+31.0 \% 5 \mathrm{p} 8 \mathrm{~s}^{1} \mathrm{P}^{\circ}$ \\
\hline 185501.0 & 185469 & & 0.81 & & $55.4 \% 5 \mathrm{p} 7 \mathrm{~d}^{3} \mathrm{D}^{\circ}+24.6 \% 5 \mathrm{p} 7 \mathrm{~d}^{1} \mathrm{P}^{\circ}$ \\
\hline 193612.7 & 193642 & & 1.13 & & $63.3 \% 5 \mathrm{p} 8 \mathrm{~s}^{1} \mathrm{P}^{\circ}+28.9 \% 5 \mathrm{p} 8 \mathrm{~s}^{3} \mathrm{P}^{\circ}$ \\
\hline 194446.8 & 194294 & & 1.28 & & $60.8 \% 5 \mathrm{p} 7 \mathrm{~d}^{3} \mathrm{P}^{\circ}+21.8 \% 5 \mathrm{p} 7 \mathrm{~d}^{3} \mathrm{D}^{\circ}$ \\
\hline \multicolumn{6}{|r|}{ 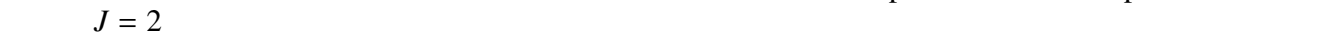 } \\
\hline 64586.5 & 64560 & & 1.98 & & $95.0 \% 5 \mathrm{~s} 5 \mathrm{p}^{3}\left({ }^{4} \mathrm{~S}\right){ }^{5} \mathrm{~S}^{\circ}+3.7 \% 5 \mathrm{~s} 5 \mathrm{p}^{3}\left({ }^{2} \mathrm{P}\right){ }^{3} \mathrm{P}^{\circ}$ \\
\hline 83203.4 & 83125 & & 1.22 & & $70.2 \% 5 \mathrm{~s} 5 \mathrm{p}^{3}\left({ }^{2} \mathrm{D}\right){ }^{3} \mathrm{D}^{\circ}+13.6 \% 5 \mathrm{p} 5 \mathrm{~d}^{3} \mathrm{D}^{\circ}$ \\
\hline 95031.3 & 94760 & & 1.17 & & $33.9 \% 5 \mathrm{p} 5 \mathrm{~d}^{1} \mathrm{D}^{\circ}+21.5 \% 5 \mathrm{~s} 5 \mathrm{p}^{3}\left({ }^{2} \mathrm{P}\right){ }^{3} \mathrm{P}^{\circ}$ \\
\hline 100469.1 & 100505 & 1.13 & 1.26 & 1.12 & $38.7 \% 5 \mathrm{~s} 5 \mathrm{p}^{3}\left({ }^{2} \mathrm{P}\right){ }^{3} \mathrm{P}^{\circ}+26.4 \% 5 \mathrm{p} 5 \mathrm{~d}^{1} \mathrm{D}^{\circ}$ \\
\hline 104717.2 & 104772 & & 0.71 & & $85.6 \% 5 \mathrm{p} 5 \mathrm{~d}^{3} \mathrm{~F}^{\circ}+4.0 \% 5 \mathrm{p} 5 \mathrm{~d}^{1} \mathrm{D}^{\circ}$ \\
\hline 115422.2 & 115513 & 1.28 & 1.47 & 1.15 & $75.6 \% 5 \mathrm{p} 6 \mathrm{~s}^{3} \mathrm{P}^{\circ}+8.7 \% 5 \mathrm{p} 5 \mathrm{~d}^{3} \mathrm{D}^{\circ}$ \\
\hline 116719.4 & 116750 & 1.34 & 1.35 & 1.01 & $30.6 \% 5 \mathrm{p} 5 \mathrm{~d}^{3} \mathrm{D}^{\circ}+30.1 \% 5 \mathrm{p} 5 \mathrm{~d}^{3} \mathrm{P}^{\circ}$ \\
\hline 122515.0 & 122440 & & 1.25 & & $40.2 \% 5 \mathrm{p} 5 \mathrm{~d}^{3} \mathrm{D}^{\circ}+24.5 \% 5 \mathrm{p} 5 \mathrm{~d}^{3} \mathrm{P}^{\circ}$ \\
\hline 127188.8 & 127455 & & 1.10 & & $48.9 \% 5 \mathrm{~s} 5 \mathrm{p}^{3}\left({ }^{2} \mathrm{D}\right){ }^{1} \mathrm{D}^{\circ}+25.6 \% 5 \mathrm{p} 5 \mathrm{~d}^{1} \mathrm{D}^{\circ}$ \\
\hline 161407.4 & 161574 & & 0.76 & & $72.8 \% 5 \mathrm{p} 6 \mathrm{~d}^{3} \mathrm{~F}^{\circ}+18.3 \% 5 \mathrm{p} 6 \mathrm{~d}^{1} \mathrm{D}^{\circ}$ \\
\hline 162745.6 & 162602 & & 1.26 & & $38.9 \% 5 \mathrm{p} 6 \mathrm{~d}^{3} \mathrm{P}^{\circ}+36.3 \% 5 \mathrm{p}^{\circ} \mathrm{d}^{3} \mathrm{D}^{\circ}$ \\
\hline 170017.4 & 170029 & & 1.49 & & $96.3 \% 5 \mathrm{p} 7 \mathrm{~s}^{3} \mathrm{P}^{\circ}+1.3 \% 5 \mathrm{p} 6 \mathrm{~d}^{1} \mathrm{D}^{\circ}$ \\
\hline 170417.2 & 170612 & & 0.98 & & $45.8 \% 5 \mathrm{p} 6 \mathrm{~d}^{1} \mathrm{D}^{\circ}+27.6 \% 5 \mathrm{p} 6 \mathrm{~d}^{3} \mathrm{D}^{\circ}$ \\
\hline 171965.0 & 171871 & & 1.35 & & $54.5 \% 5 \mathrm{p} 6 \mathrm{~d}^{3} \mathrm{P}^{\circ}+26.8 \% 5 \mathrm{p} 6 \mathrm{~d}^{3} \mathrm{D}^{\circ}$ \\
\hline 184408.8 & 184588 & & 0.76 & & $75.8 \% 5 \mathrm{p} 7 \mathrm{~d}^{3} \mathrm{~F}^{\circ}+18.1 \% 5 \mathrm{p} 7 \mathrm{~d}^{1} \mathrm{D}^{\circ}$ \\
\hline 185193.7 & 185081 & & 1.29 & & $45.8 \% 5 \mathrm{p} 7 \mathrm{~d}^{3} \mathrm{P}^{\circ}+34.8 \% 5 \mathrm{p}^{\circ} \mathrm{d}^{3} \mathrm{D}^{\circ}$ \\
\hline 193414.9 & 193397 & & 1.49 & & $96.6 \% 5 \mathrm{p} 8 \mathrm{~s}^{3} \mathrm{P}^{\circ}+1.4 \% 5 \mathrm{p} 7 \mathrm{~d}^{3} \mathrm{P}^{\circ}$ \\
\hline 193745.5 & 193759 & & 0.98 & & $50.5 \% 5 \mathrm{p} 7 \mathrm{~d}^{1} \mathrm{D}^{\circ}+26.1 \% 5 \mathrm{p} 7 \mathrm{~d}^{3} \mathrm{D}^{\circ}$ \\
\hline \multicolumn{6}{|r|}{ 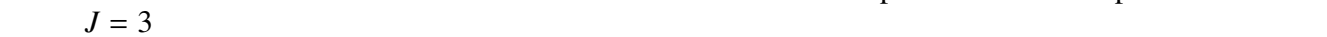 } \\
\hline 85205.6 & 85251 & & 1.33 & & $81.4 \% 5 \mathrm{~s} 5 \mathrm{p}^{3}\left({ }^{2} \mathrm{D}\right){ }^{3} \mathrm{D}^{\circ}+15.6 \% 5 \mathrm{p} 5 \mathrm{~d}^{3} \mathrm{D}^{\circ}$ \\
\hline 106314.8 & 106472 & 1.07 & 1.09 & 1.02 & $92.4 \% 5 \mathrm{p} 5 \mathrm{~d}^{3} \mathrm{~F}^{\circ}+1.6 \% 5 \mathrm{p}^{3}\left({ }^{2} \mathrm{P}\right) 5 \mathrm{~d}^{3} \mathrm{~F}^{\circ}$ \\
\hline 120903.4 & 120729 & 1.35 & 1.31 & 0.97 & $74.0 \% 5 \mathrm{p} 5 \mathrm{~d}^{3} \mathrm{D}^{\circ}+13.4 \% 5 \mathrm{~s} 5 \mathrm{p}^{3}\left({ }^{2} \mathrm{D}\right){ }^{3} \mathrm{D}^{\circ}$ \\
\hline 127242.3 & 127539 & & 1.02 & & $87.7 \% 5 \mathrm{p} 5 \mathrm{~d}^{1} \mathrm{~F}^{\circ}+4.7 \% 5 \mathrm{p} 5 \mathrm{~d}^{3} \mathrm{D}^{\circ}$ \\
\hline 162776.6 & 162844 & & 1.13 & & $53.0 \% 5 \mathrm{p} 6 \mathrm{~d}^{3} \mathrm{~F}^{\circ}+24.1 \% 5 \mathrm{p} 6 \mathrm{~d}^{3} \mathrm{D}^{\circ}$ \\
\hline 171069.7 & 170949 & & 1.24 & & $61.5 \% 5 \mathrm{p} 6 \mathrm{~d}^{3} \mathrm{D}^{\circ}+33.5 \% 5 \mathrm{p} 6 \mathrm{~d}^{3} \mathrm{~F}^{\circ}$ \\
\hline 173220.2 & 173245 & & 1.04 & & $75.0 \% 5 \mathrm{p} 6 \mathrm{~d}^{1} \mathrm{~F}^{\circ}+9.9 \% 5 \mathrm{p} 6 \mathrm{~d}^{3} \mathrm{D}^{\circ}$ \\
\hline 185347.4 & 185307 & & 1.12 & & $49.8 \% 5 \mathrm{p} 7 \mathrm{~d}^{3} \mathrm{~F}^{\circ}+25.2 \% 5 \mathrm{p} 7 \mathrm{~d}^{1} \mathrm{~F}^{\circ}$ \\
\hline 193930.5 & 193899 & & 1.24 & & $60.4 \% 5 \mathrm{p} 7 \mathrm{~d}^{3} \mathrm{D}^{\circ}+37.15 \mathrm{p} 7 \mathrm{~d}^{3} \mathrm{~F}^{\circ}$ \\
\hline \multirow{2}{*}{$\begin{array}{r}194800.0 \\
J=4\end{array}$} & 194932 & & 1.06 & & $71.9 \% 5 \mathrm{p} 7 \mathrm{~d}^{1} \mathrm{~F}^{\circ}+14.65 \mathrm{p} 7 \mathrm{~d}^{3} \mathrm{D}^{\circ}$ \\
\hline & 110385 & & 1.25 & & $95.9 \% 5 \mathrm{p} 5 \mathrm{~d}^{3} \mathrm{~F}^{\circ}+1.7 \% 5 \mathrm{~s} 5 \mathrm{p}^{3}\left({ }^{2} \mathrm{P}\right) 5 \mathrm{~d}^{3} \mathrm{~F}^{\circ}$ \\
\hline
\end{tabular}

Notes. ${ }^{(a)}$ Tauheed \& Naz (2011). ${ }^{(b)}$ HFR + CPOL (this work). ${ }^{(c)}$ Kramida et al. (2012). 


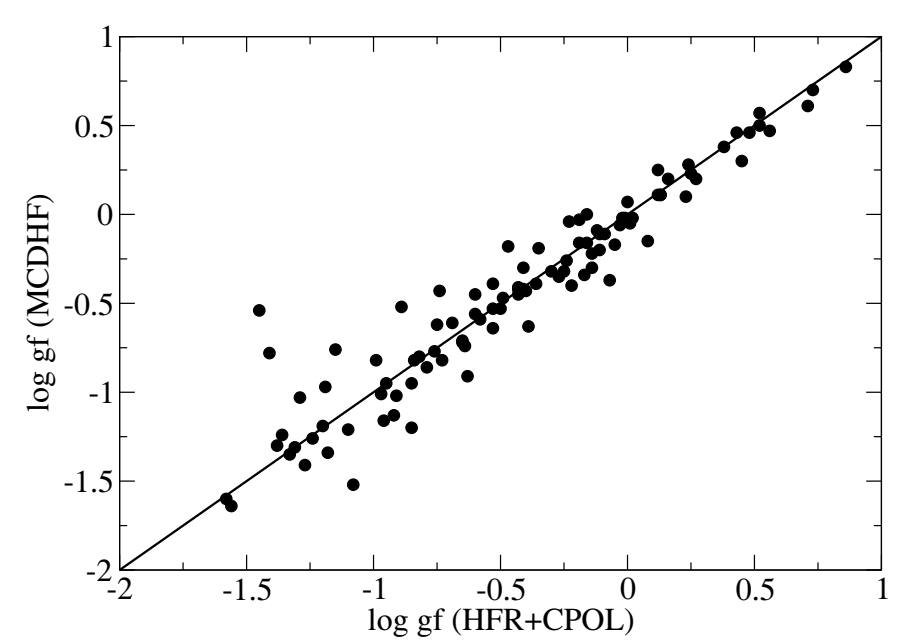

Fig. 1. Comparison between MCDHF and HFR+CPOL $\log g f$ in Te II. Transitions with $C F>0.05$ and gauges agreements better than $10 \%$ have been retained. A straight line of equality has been drawn.

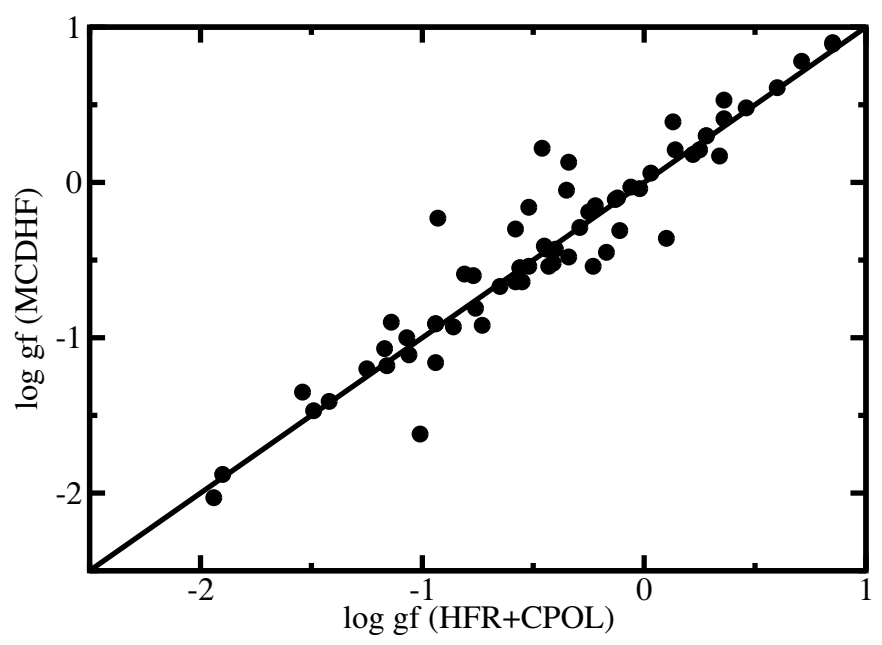

Fig. 2. Same as in Fig. 1 for Te III.

comparison of the results obtained by two independent theoretical approaches, i.e. the HFR+CPOL and the MCDHF approximations. The satisfying agreement which is observed indicates that the scale of $f$ values is firmly established. This new set of results is expected to help the astrophysicists in the investigation of VUV high resolution spectra and hopefully will contribute to throw some light on nucleosynthesis processes regarding the production of heavy elements in metal-poor stars.

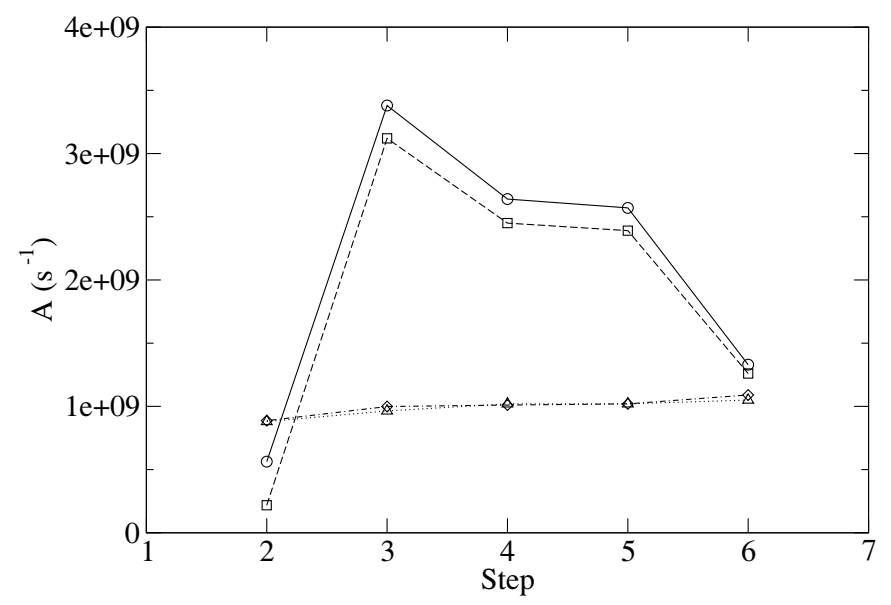

Fig. 3. $A$-values in both gauges (circles and squares for Babushkin and Coulomb gauges) of the $5 \mathrm{~s}^{2} 5 \mathrm{p}^{2}{ }^{3} \mathrm{P}_{1}-5 \mathrm{~s}^{2} 5 \mathrm{p} 6 \mathrm{~s}^{1} \mathrm{P}_{1}^{\mathrm{o}}$ transition in Te III along with those of $5 \mathrm{~s}^{2} 5 \mathrm{p}^{2}{ }^{3} \mathrm{P}_{2}-5 \mathrm{~s}^{2} 5 \mathrm{p} 6 \mathrm{~s}^{3} \mathrm{P}_{1}^{\mathrm{o}}$ transition in the same ion (diamonds for Babushkin and triangles for Coulomb) plotted as function of the calculation step. The first transition shows a convergence problem.

Acknowledgements. Financial support from the belgian FRS-FNRS is acknowledged. P.P., P.Q. and E.B. are respectively Research Associate, Research Director and Honorary Research Director of this organization.

\section{References}

Biémont, E., Hansen, J. E., Quinet, P., \& Zeippen, C. J. 1995, A\&AS, 111, 333 Cowan, R. D. 1981, The Theory of Atomic Structure and Spectra (Berkeley: University of California Press)

Cowley, C. H., Hartoog, M. R., Aller, M. F., \& Cowley, A. P. 1973, ApJ, 183, 127

Crooker, A. M., \& Joshi, Y. N. 1964, JOSA, 54553

Eriksson, K. B. S. 1974, J. Opt. Soc. Am., 64, 1272

Grant, I. P. 1988, in Methods of Computational Chemistry, ed. S. Wilson (New York: Plenum Press), 2, 1

Handrup, M. B., \& Mack, J. E. 1964, Physica (Utrecht), 30, 1245

Jonsson, P., He, X., Froese Fischer, C., \& Grant, I. P. 2007, Comput. Phys. Commun., 177, 597

Joshi, Y. N., Tauheed, A., \& Davison I. G. 1992, Can. J. Phys., 70, 740

Kramida, A., Ralchenko, Yu., Reader, J., and NIST ASD Team 2012, NIST Atomic Spectra Database (ver. 5.0), available: http://physics.nist. gov/asd, National Institute of Standards and Technology, Gaithersburg, MD Krishnamurty, S. G., \& Rao, K. R. 1937, Proc. R. Soc. London Ser. A, 158, 562 Roederer, I. U. , Lawler, J. E. , Cowan, J. J., et al. 2012, ApJ, 747, L8 Tauheed, A., Joshi, Y. N., \& Steinitz, M. 2009, Can. J. Phys., 87, 1255 Tauheed, A., \& Naz, A. 2011, J. Korean Phys. Soc., 59, 2910

Werel, K., \& Augustyniak, L. 1981, Phys. Scr., 23, 856 